University of Wollongong

Research Online

Faculty of Engineering and Information

Faculty of Engineering and Information

Sciences - Papers: Part A

Sciences

$1-1-2015$

In situ powder diffraction studies of electrode materials in rechargeable batteries

Neeraj Sharma

University of New South Wales

Wei Kong Pang

University of Wollongong, wkpang@uow.edu.au

Zaiping Guo

University of Wollongong, zguo@uow.edu.au

Vanessa K. Peterson

Australian Nuclear Science And Technology Organisation, vep@ansto.gov.au

Follow this and additional works at: https://ro.uow.edu.au/eispapers

Part of the Engineering Commons, and the Science and Technology Studies Commons

Research Online is the open access institutional repository for the University of Wollongong. For further information contact the UOW Library: research-pubs@uow.edu.au 


\title{
In situ powder diffraction studies of electrode materials in rechargeable batteries
}

\begin{abstract}
The ability to directly track the charge carrier in a battery as it inserts/extracts from an electrode during charge/discharge provides unparalleled insight for researchers into the working mechanism of the device. This crystallographic-electrochemical information can be used to design new materials or modify electrochemical conditions to improve battery performance characteristics, such as lifetime. Critical to collecting operando data used to obtain such information insitu while a battery functions are X-ray and neutron diffractometers with sufficient spatial and temporal resolution to capture complex and subtle structural changes. The number of operando battery experiments has dramatically increased in recent years, particularly those involving neutron powder diffraction. Herein, the importance of structure-property relationships to understanding battery function, why insitu experimentation is critical to this, and the types of experiments and electrochemical cells required to obtain such information are described. For each battery type, selected research that showcases the power of insitu and operando diffraction experiments to understand battery function is highlighted and future opportunities for such experiments are discussed. The intention is to encourage researchers to use insitu and operando techniques and to provide a concise overview of this area of research.
\end{abstract}

\section{Keywords}

situ, batteries, diffraction, studies, powder, electrode, materials, rechargeable

Disciplines

Engineering | Science and Technology Studies

\section{Publication Details}

Sharma, N., Pang, W. Kong., Guo, Z. \& Peterson, V. K. (2015). In situ powder diffraction studies of electrode materials in rechargeable batteries. ChemSusChem: chemistry and sustainability, energy and materials, 8 (17), 2826-2853. 


\section{Intua In Situ Powder Diffraction Studies of Electrode Materials in Rechargeable Batteries}

Neeraj Sharma, ${ }^{*[a]}$ Wei Kong Pang, ${ }^{[b, c]}$ Zaiping Guo, ${ }^{[c]}$ and Vanessa K. Peterson ${ }^{[b]}$
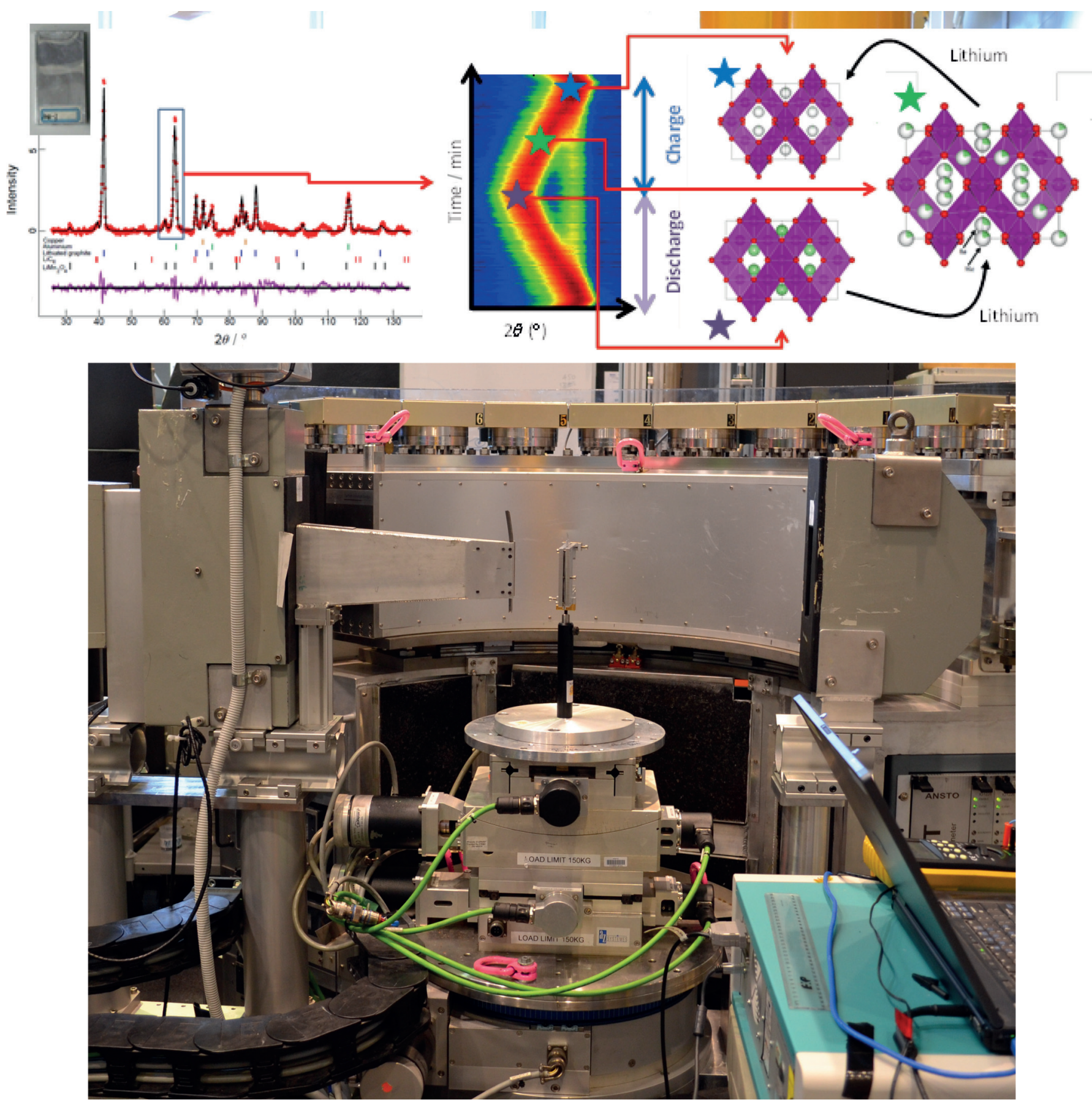
The ability to directly track the charge carrier in a battery as it inserts/extracts from an electrode during charge/discharge provides unparalleled insight for researchers into the working mechanism of the device. This crystallographic-electrochemical information can be used to design new materials or modify electrochemical conditions to improve battery performance characteristics, such as lifetime. Critical to collecting operando data used to obtain such information in situ while a battery functions are X-ray and neutron diffractometers with sufficient spatial and temporal resolution to capture complex and subtle structural changes. The number of operando battery experiments has dramatically increased in recent years, particularly those involving neutron powder diffraction. Herein, the importance of structure-property relationships to understanding battery function, why in situ experimentation is critical to this, and the types of experiments and electrochemical cells required to obtain such information are described. For each battery type, selected research that showcases the power of in situ and operando diffraction experiments to understand battery function is highlighted and future opportunities for such experiments are discussed. The intention is to encourage researchers to use in situ and operando techniques and to provide a concise overview of this area of research.

\section{Batteries and Energy Storage}

Increasing worldwide need for energy is depleting our main energy sources, including fossil fuels such as coal, petroleum, and natural gas. Concurrently, the combustion of fossil fuels is increasing harmful greenhouse gas emissions and other environmental pollutants. Renewable and sustainable energy is required to solve such problems. To enable renewable energy, energy conversion and storage systems are essential to smooth out the intermittent nature of generation. There are a number of energy-conversion and storage systems (e.g., flywheels), but lithium-ion rechargeable batteries are proving to be the dominant rechargeable battery system. This is because of their high energy density, high power density, and higher operating voltage compared with other rechargeable batteries, such as lead-acid and widely used nickel-metal-hybrid batteries.

The major application that batteries and energy-storage devices find ubiquitous use in is portable electronics. Batteries have enabled the further development of these and have thus changed how we live, communicate, and access information in the world today. Other applications of batteries include vehicles, aircraft, spacecraft, toothbrushes, and children's toys.

\section{Battery Types}

The first-generation electrochemical cells were discovered by Luigi Galvani in the 1790s and Alessandro Volta in the 1800 s.

[a] Dr. N. Sharma

School of Chemistry, UNSW Australia

Sydney, NSW 2052 (Australia)

E-mail: neeraj.sharma@unsw.edu.au

[b] Dr. W. K. Pang, Dr. V. K. Peterson

Australian Nuclear Science and Technology Organisation Locked Bag 2001, Kirrawee DC, NSW 2232 (Australia)

[c] Dr. W. K. Pang, Prof. Z. Guo

School of Mechanical, Materials, and Mechatronic Engineering

Institute for Superconducting \& Electronic Materials

Faculty of Engineering, University of Wollongong NSW 2522 (Australia)

tanting This publication is part of a Special Issue on the "Future Energy" conference in Sydney, Australia. To view the complete issue, visit: http://onlinelibrary.wiley.com/doi/10.1002/cssc.v8.17/issuetoc.
Galvani believed that animals could generate electricity, and Volta showed that electricity could be produced from a "voltaic pile". Both theories involved two different metals, such as zinc, silver, and copper. ${ }^{[1]}$ In 1866, Georges-Lionel Leclanché put forward his cell concept, in which the cell contained a zinc rod as an anode, a manganese oxide-carbon mixture as the cathode, and aqueous ammonium chloride as the electrolyte to form a battery. Leclanché's discovery promoted the development of primary batteries commonly known as carbon-zinc and alkaline cells. At the same time, the first rechargeable battery, the lead-acid battery, was invented by Gaston Plantè in 1859 . When battery evolution arrived in the twentieth century, several types of rechargeable batteries were discovered, including the nickel-cadmium battery developed by the Swedish engineer Waldmar Jungner in 1901, the nickel-iron battery by Thomas Edison in 1901, and the nickel-metal hydride (NiMH) battery in 1975.

Today batteries have become an integral part of our lives, and different battery chemistries are used for different applications. Batteries can be divided initially into two categories, primary and secondary batteries, that are one-time use and rechargeable batteries, respectively. Common chemistries for primary batteries include zinc-carbon, alkaline, and lithium batteries. The zinc-carbon battery is the least expensive battery and often comes with consumer devices when batteries are included. A zinc-carbon battery is constructed with a zinc shell that serves as the anode; a graphite rod that serves as the cathode; and a moist mixture of ammonium chloride, zinc chloride, and manganese dioxide. The half-reaction that occurs on the anode when the battery delivers current is the oxidation of zinc: $\mathrm{Zn}_{(\mathrm{s})} \rightarrow \mathrm{Zn}^{2+}{ }_{(\mathrm{aq})}+2 \mathrm{e}^{-}$. The half-reaction that occurs simultaneously on the cathode is the reduction of ammonium ions: $2 \mathrm{e}^{-}+2 \mathrm{NH}_{4}{ }^{+}$(aq, moist paste) $\rightarrow 2 \mathrm{NH}_{3(\mathrm{~g})}+\mathrm{H}_{2(\mathrm{~g})}$. The overall reaction in a zinc-carbon cell can be represented by Equation (1):

$$
\begin{aligned}
\mathrm{Zn}_{(\mathrm{s})}+2 \mathrm{MnO}_{2(\mathrm{~s})}+2 \mathrm{NH}_{4} \mathrm{Cl}_{(\mathrm{aq})} \rightarrow \\
\mathrm{Mn}_{2} \mathrm{O}_{3(\mathrm{~s})}+\mathrm{Zn}\left(\mathrm{NH}_{3}\right)_{2} \mathrm{Cl}_{2(\mathrm{aq})}+\mathrm{H}_{2} \mathrm{O}_{(\mathrm{l})}
\end{aligned}
$$

The alkaline battery is recognized to have several advantages over carbon-zinc-type batteries, such as higher energy density, superior service performance at all drain rates, superior cold temperature performance, and lower internal resistance. 
In an alkaline battery, the negative electrode is zinc and the positive electrode is manganese dioxide. An alkaline battery produces electricity when the manganese dioxide cathode is reduced and the zinc anode is oxidized. The reaction for a simple alkaline cell is given by Equation (2):

$\mathrm{Zn}+2 \mathrm{MnO}_{2}+\mathrm{H}_{2} \mathrm{O} \rightarrow \mathrm{ZnO}+2 \mathrm{MnOOH}$

Lithium batteries are disposable (primary) batteries that have lithium metal or lithium-containing compounds as an anode. The most common type of lithium cell uses metallic lithium as the anode and manganese dioxide as the cathode, with a lithium salt dissolved in an organic solvent. These lithium batteries are fire hazards when they are short-circuited due to the growth of dendritic lithium or if they are somehow damaged.

Secondary batteries were invented to be more cost-efficient over the longer term. The lead-acid system is one of the

Dr. Neeraj Sharma received his doctorate from the University of Sydney (Australia) in 2010 for working on the structure and properties of a range of bismuth oxides. He undertook his postdoctoral work at the Australian Nuclear Science and Technology Organisation (ANSTO), investigating the structural evolution of electrode materials in lithium-ion batteries. In 2012, he was appointed as a Lecturer and re-

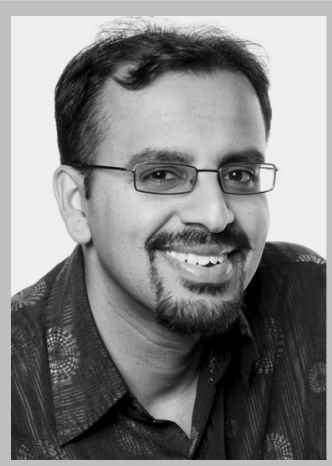
ceived the Australian Institute of $\mathrm{Nu}$ clear Science and Engineering (AINSE) research fellowship at the School of Chemistry, UNSW Australia. His group now investigates solid-state materials pertinent for battery and other applications by bringing the power of in situ characterization to these materials and devices.

Dr. Wei Kong Pang received his Ph.D. in Applied Physics from Curtin University, Western Australia, in 2011. As a joint postdoctoral research fellow, he then focused on the research and development of Li-ion batteries at the National Taiwan University and the Department of Materials Engineering at Tatung University, Taiwan. Since June 2013, he has been a joint postdoctoral fellow at University of Wollongong and Australian Nuclear Science and

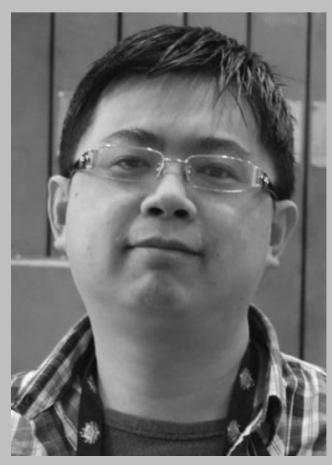

Technology Organization. His main focus is the crystallography of materials for energy-storage applications and understanding their structure-function relationships. This includes understanding the insertion/extraction mechanism and working principles of the electrode materials for both $\mathrm{Li}$ - and $\mathrm{Na}$-ion batteries by using a variety of in situ techniques. oldest rechargeable battery systems. A lead-acid cell consists of a lead anode and a lead dioxide cathode immersed in sulfuric acid. The total reaction occurring in these systems can be written as Equation (3):

$\mathrm{Pb}_{(\mathrm{s})}+\mathrm{PbO}_{2(\mathrm{~s})}+2 \mathrm{H}_{2} \mathrm{SO}_{4(\mathrm{aq})} \rightarrow 2 \mathrm{PbSO}_{4(\mathrm{~s})}+2 \mathrm{H}_{2} \mathrm{O}_{(\mathrm{l})}$

which has a working voltage of $2 \mathrm{~V}$. However, lead-acid batteries suffer from a low specific energy (33-42 $\mathrm{Wh} \mathrm{kg}^{-1}$ ) and limited cycle life.

Compared with lead-acid batteries, nickel-cadmium batteries feature advantages such as long service life, high discharge current, higher specific energy $\left(40-60 \mathrm{Wh} \mathrm{kg}^{-1}\right)$, and extreme temperature operation. Nickel-cadmium batteries use nickel oxide hydroxide and metallic cadmium as electrodes with an alkaline electrolyte. Their reaction during operation can be

Prof. Z. P. Guo received her Ph.D. in Materials Engineering from the University of Wollongong in December 2003. She is a Professor of the School of Mechanical, Materials, and Mechatronic Engineering, University of Wollongong, and is an Australian Research Council Queen Elizabeth II Fellow. Her research focuses on the design and application of nanomaterials for energy storage and conversion, including rechargeable batteries, hydrogen storage, and fuel cells.

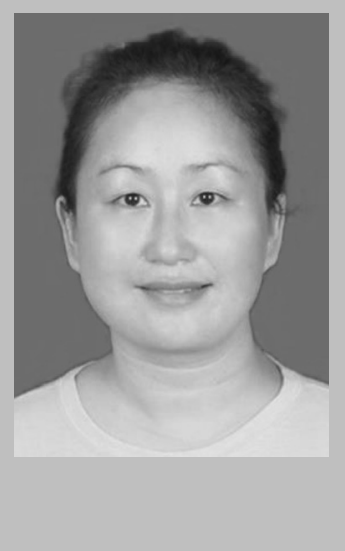

Dr. Vanessa Peterson gained her doctorate at the University of Technology, Sydney, in 2004. After two years at the NIST Center for Neutron Research (USA) she returned to Australia to work in the Department of Chemistry at the University of Sydney. In 2008, she joined ANSTO's OPAL reactor facility in Australia, where as part of the neutron powder diffraction team she commissioned, operates, and further develops two diffractometers, includ-

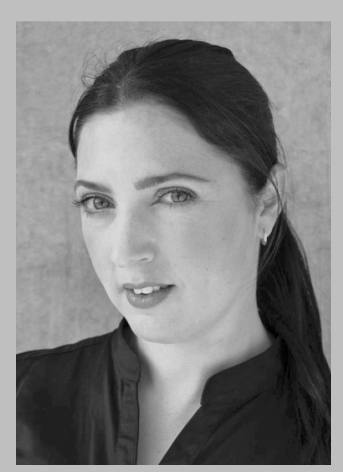
ing the specialist sample environments required for functional-materials research. Established in 2009, she leads the Energy Materials research group at the OPAL reactor facility that uses neutrons to study materials used in alternative and sustainable-energy technologies, including batteries, porous sorbents, as well as fuel and solar cell materials. 
written as Equation (4), and they produce a low voltage of $1.2 \mathrm{~V}$ :

$2 \mathrm{NiO}(\mathrm{OH})+\mathrm{Cd}+2 \mathrm{H}_{2} \mathrm{O} \leftrightarrow 2 \mathrm{Ni}(\mathrm{OH})_{2}+\mathrm{Cd}(\mathrm{OH})_{2}$

Due to environmental concerns, the nickel-cadmium battery is being replaced with other chemistries for the cadmium-containing electrode. The NiMH battery is a practical replacement for $\mathrm{Ni}-\mathrm{Cd}$ due to the higher specific energy $\left(60-120 \mathrm{Wh} \mathrm{kg}^{-1}\right.$; three times the capacity of an equivalently sized $\mathrm{Ni}-\mathrm{Cd}$ system) with fewer toxic metals. NiMH batteries use nickel oxyhydroxide as the positive electrode and hydrogen-absorbing alloy as the negative electrode. The negative electrode reaction occurring in a NiMH cell is $\mathrm{H}_{2} \mathrm{O}+\mathrm{M}+\mathrm{e}^{-} \leftrightarrow \mathrm{OH}^{-}+\mathrm{MH}$, in which $\mathrm{M}$ refers to the alloy. On the positive electrode, nickel oxyhydroxide is formed: $\mathrm{Ni}(\mathrm{OH})_{2}+\mathrm{OH}^{-} \leftrightarrow \mathrm{NiO}(\mathrm{OH})+\mathrm{H}_{2} \mathrm{O}+\mathrm{e}^{-}$.

In the 1970s, the lithium-ion battery was developed due to the expanding demand for electrical devices. These featured a high energy density, no memory effect, and only a slow loss of charge when not in use. Lithium-ion batteries typically use an intercalated lithium compound as one electrode material. In 1980, Goodenough and co-workers discovered the family of $\mathrm{Li}_{x} \mathrm{MO}_{2}(\mathrm{M}=\mathrm{Co}, \mathrm{Ni}, \mathrm{Mn})$ compounds as cathode materials, which could be regarded as "lithium sources" to provide lithium ions to the negative intercalation electrode acting as a "lithium sink". ${ }^{[2]}$ The battery system concept in which lithium ions can transfer between the two intercalation electrodes is called the lithium rocking-chair battery. The concept was utilized for the practical application of the graphite || $\mathrm{LiCoO}_{2}$ cell by Sony in $1991 .^{[3]}$ This new type of battery was renamed the lithiumion battery and had a strong impact on battery research, applications, and the user community all over the world due to its high operating voltage. A comparison of different battery technologies in terms of volumetric and gravimetric energy density is shown in Figure 1.

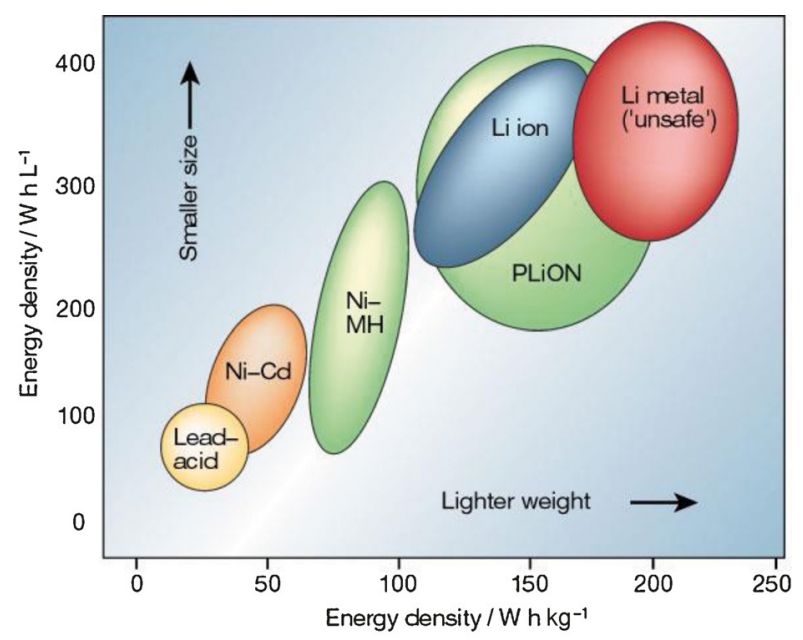

Figure 1. Comparison of different battery technologies in terms of volumetric and gravimetric energy density. ${ }^{[4]}$

\section{Exploring Structure-Property Relationships}

Understanding the fundamental properties of materials and their functionality at the atomic and molecular level is crucial in paving the way for the future design of materials with improved performance characteristics. The structure-function relationship is at the heart of this understanding and involves gaining information concerning the structure and its evolution, ideally alongside electrochemical performance measurements.

\subsection{Electrodes and their evolution}

Depending on the battery type and requirements placed on the battery performance, the crystal structures of electrode materials are diverse. Crystal structures containing layers, such as graphite and $\mathrm{LiCoO}_{2}{ }^{[5]}$ are common and during insertion/extraction reactions the cations can insert and are removed from certain layers. These often feature 2D pathways for the charge carriers. Examples also exist for species with 1D pathways, such as olivine $\mathrm{LiFePO}_{4}{ }^{\left[{ }^{[6]}\right.}$ and $3 \mathrm{D}$ pathways, such as spinel $\mathrm{Li}_{4} \mathrm{Ti}_{5} \mathrm{O}_{12}$ and $\mathrm{LiMn}_{2} \mathrm{O}_{4}{ }^{[7]}$ for the charge carriers. In terms of the variety of compounds as electrodes, these range from semimetals to fluorophosphates and complex frameworks. ${ }^{[4,8]}$

Electrodes are often engineered to optimize performance parameters. Typical electrodes for lithium- and sodium-ion batteries contain a mixture of the active material, a binder to hold the particles together and onto the current collector, and a carbon-based conductive matrix to ensure conductivity between active material particles and the current collector. ${ }^{[9]}$ Although researchers are working on complex core-shell morphologies of the active materials ${ }^{[10]}$ or composite electrodes ${ }^{[11]}$ and binder-free approaches, ${ }^{[12]}$ constructing the electrode at the macroscopic level plays a significant role in battery performance. Thus, incorporating macroscopic and atomic-level detail from crystallographic studies in a holistic approach will lead to better batteries.

What structural changes occur in an electrode during battery function? If we take lithium-ion batteries with insertion electrodes as an example, positively charged lithium ions are extracted from the positive electrode and transferred via the electrolyte and inserted into the negative electrode during charging. In conjunction with this is the need for the oxidation state of one or more of the other elements in the electrode to change. The insertion and extraction of $\mathrm{Li}^{+}$and change in the oxidation state will influence the structure of the host electrodes. The simplest change may be an expansion or contraction of one or more axes of the crystallographic unit cell, which may result in a volume change. So, as the battery is charged, the positive electrode may expand. For example, in $\mathrm{LiCoO}_{2}$ positive electrodes, the structure consists of layers of $\mathrm{Li}^{+}$and negatively charged edge-sharing $\mathrm{CoO}_{6}$ octahedra. The initial charge results in an expansion of the $c$ unit-cell parameter, which is the stacking axis, as the negatively charged $\mathrm{CoO}_{6}$ layers repel each other when $\mathrm{Li}^{+}$is removed. ${ }^{[5 a, b]}$ This is typical of a solid-solution or second-order phase transition in which the unit cell changes during ion insertion or extraction. In diffraction pat- 
terns, the solid-solution reaction can be observed through changes in the reflection position. ${ }^{[5 c]}$

An alternative reaction during ion insertion/extraction could be the nucleation and growth of a second phase at the expense of the primary phase; this is a two-phase or first-order phase transition. Graphite negative electrodes show this structural behavior near the charged state of lithium-ion batteries, with $\mathrm{LiC}_{12}$ transforming into $\mathrm{LiC}_{6}$, as shown by a loss in the intensity of the $\mathrm{LiC}_{12}$ reflections and a corresponding increase in intensity of the $\mathrm{LiC}_{6}$ reflections. ${ }^{[5 a, c, 13]}$ This is in response to a smaller amount of $\mathrm{LiC}_{12}$ relative to $\mathrm{LiC}_{6}$ in the electrode as the phase transition progresses. In addition to the appearance of new reflections associated with the formation of new phases (two-phase reactions) and the change in the position of reflections (solid-solution reactions), some reflections may change in intensity, whereas others do not (or not to the same extent); this is indicative of changes in the atomic distribution within the electrode. Furthermore, all of these processes can occur simultaneously, which complicates analysis and interpretation.

Electrodes can undergo other types of reactions during battery function, such as alloying or conversion. An example of a conversion reaction is the reaction of $\mathrm{Li}$ with $\mathrm{SnO}_{2}$ to produce $\mathrm{Li}_{2} \mathrm{O}$ and $\mathrm{Sn}$, and these reactions are often associated with dramatic volume changes. Interestingly, recent work also shows that the Sn produced above can react with more Li through alloying reactions to produce $\mathrm{Li}_{y} \mathrm{Sn} .{ }^{[14]}$ If the materials that make up the electrode or the products of the electrochemical reaction are not crystalline (long-range ordered), a diffraction experiment will not be very informative. The exception is if researchers are looking to find out "when" the electrode turns amorphous or loses crystallographic order. ${ }^{[15]}$ In practical terms, some nanocrystalline electrodes can be problematic to probe; however, this depends on the material, instrument, and research questions posed.

For crystalline components, the observed changes in the diffraction patterns inform researchers about the original structure, for example, layered, how that structure evolves and the types of reaction mechanisms, and how the atomic distribution changes. All of these parameters underpin battery performance and provide information on tuning of the battery performance by chemically altering the makeup of the electrode material or the electrochemical conditions of battery use.

\subsection{Types of experiments}

Ultimately, the level of detail gained is a compromise between the structure and its evolution. Consequently, experiments aimed at understanding the structure-function relationship in materials can take one of two broad approaches, involving equilibrated or non-equilibrated systems. A further division of studies exists within these two approaches: studies examining each material as a single component or model system, and those examining these components within a whole assembled device.

By way of example, typical structure-function relationship studies of batteries materials in each of these categories in- clude 1) equilibrium single-component studies (ex situ), such as examining the electrode powder structure as a function of composition or temperature; 2) equilibrium whole-assembled studies (in situ), such as examining electrode structure within a battery at particular states of charges; 3) non-equilibrium model-system studies (in situ/operando), such as examining the electrode structure during its reaction with various electrolytes, 4) non-equilibrium whole-device studies (operando), such as examining electrode structure in a battery during charge/ discharge.

Broadly speaking, examples 1-4 above are ordered from easiest to hardest to successfully perform. The difficulty in realizing the experiments and data analyzes are typically offset by similarly ordered increases in structure-function understanding to be gained.

Equilibrium single-component studies are usually not standalone, but instead form the foundation for more complex studies. A dedicated, single-component study allows a detailed structural understanding to be gained that underpins more difficult to understand data, such as that collected rapidly and/or from multicomponent systems. Such information is usually correlated with ex situ determined performance, for which the structure-function relationship is explored with variables that can include composition or temperature.

Understanding the working mechanism of an electrode is the key to advancing new battery technologies, and central to achieving this is the study of materials during their operation. Insights into the phase evolution and mechanism of charge transfer within batteries pave the way for new materials to be developed and also point to operational efficiency, such as by defining charge and current limits. The in situ approach has been extended in recent years to operando studies, in which materials are studied under non-equilibrium, real-time conditions (literally, in operation). These studies are exceptionally powerful in gaining insights into structural evolution, and therefore, function, and are represented by the type of studies outlined in 2-4 above. In particular, operando studies on nonequilibrated systems allow the structure to be explored as a function of time, which enables kinetic information to be derived.

The corresponding information gained in each of the typical structure-function relation studies outlined above include a) ex situ studies, which are more detailed structures than in 2-4, and provide no detail on component evolution during function; b) in situ studies, which provide fewer structural details than 1 and more than 3 and 4, although electrode function insights that are less time-correlated than those of 3 and 4 ; this provides information that is sometimes an essential bridge to 3 and 4 ; c) operando studies, which provide less detailed structural insights than 1, but more detailed evolution insights than 4; and d) operando studies, which provide less detailed structural insights than 1-3, but more detailed evolution insights, which are obtained under relevant working conditions.

The exploration of structure-property relationships is essential in battery materials research, as demonstrated by the surge of experimental studies in this area over the last decade, which 
are driven by the requirement for cleaner and higher performance batteries. The level of detail gained on both the material's structure and evolution during battery function is increasing in parallel with this research surge as experimental methods mature.

\section{Diffraction Techniques}

Both atomic- and large-scale structures are important to understand battery materials. Of the diffraction methods used to gain this information, powder diffraction is the most popular and has been used extensively in the study of battery material structures.

Electrodes are arguably the most important functional material within a battery and conventional powder diffraction is commonly used for the determination of their crystallographic structure. The measured quantity in a diffraction experiment is the structure factor, $S(Q)$, which describes scattered X-rays or neutrons in terms of the wave-vector transfer $(Q)$, the angle of the scattered beam $(\theta)$, and the incident wavelength $(\lambda)$, through Bragg's Law, in which $Q=4 \pi \sin \theta / \lambda$. For a single crystal, the scattering will consist of Bragg peaks. In an ideal powder sample, small crystallites are randomly oriented and scattering from a particular set of lattice planes corresponds to scattering obtained by turning a single crystal. In powder samples, Debye-Scherrer cones are obtained in place of Bragg peaks. Powder diffraction is an established tool for atomic- and molecular-scale structural characterization and has been developed to the point where complete structural information can be obtained from polycrystalline samples.

Nanosizing is particularly important in electrode materials, which results in structures that are sometimes not easily studied by means of conventional powder diffraction. Traditional diffraction considers the long-range average structure, whereas total scattering, as implemented in the pair-distribution function (PDF), uses both Bragg and diffuse scattering and is sensitive to local environments. ${ }^{[16]}$ The PDF $G(r)$ gives the probability of finding an atom at a given distance, $r$, from another atom and can give information about local ordering. To investigate the phase transformation at the local atomic scale, PDF analysis of total-scattering data is useful in studying electrode materials, for which it can be used to determine local structures in a way that is sensitive to relatively long-range correlations.

Generally speaking, the diffraction method and source chosen is guided by the requirements of the material under characterization, alongside the temporal and spatial resolution required.

\subsection{Sources}

Of the types of diffraction sources, laboratory-based X-ray powder diffraction (XRPD) is easiest to both access and use. Inhouse laboratory-based X-ray diffractometers can be tailored and customized for battery-specific studies, which helps to overcome in situ and operando demands. However, the structural complexity of many battery materials leads to the requirement for higher resolution and high flux sources. The higher flux offered by synchrotron sources translates directly into higher spatial and temporal resolution and so synchrotron XRPD (SXRPD) is the next step in the characterization of these materials and has been used extensively for this purpose.

Neutrons interact with, and are sometimes scattered by, atomic nuclei, which is different to the way that X-rays interact and scatter. This leads to two overall and very important advantages for the study of battery material structure by using neutron powder diffraction (NPD):

First, the neutron scattering characteristics of each type of isotopic nucleus vary from one isotope type to another. This provides considerable scope for measuring light nuclei in the presence of very heavy nuclei, and also changing the scattering length by using a different isotope of the same element. For lithium-ion battery electrodes, this allows lithium to be probed in the presence of transition metals, which is a considerable advantage over X-ray diffraction (XRD), in which scattering arises from electron density. Figure 2 shows an example of

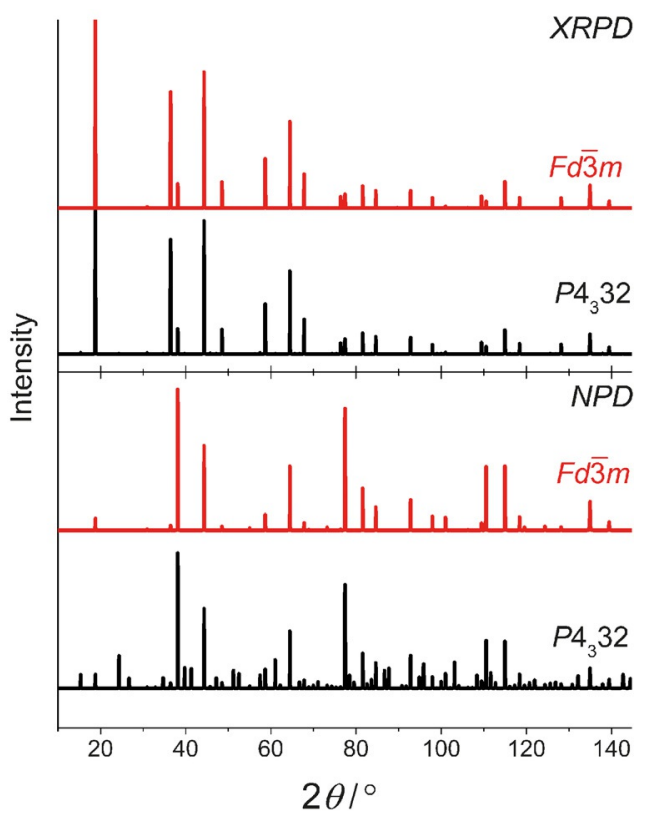

Figure 2. Simulated XRPD and NPD patterns of ordered $\mathrm{P}_{3} 32$ and disordered $\mathrm{Fd} \overline{3} \mathrm{~m}$ structures of $\mathrm{LiNi}_{0.5} \mathrm{Mn}_{1.5} \mathrm{O}_{4}$.

this, for which XRPD cannot distinguish between $\mathrm{LiNi}_{0.5} \mathrm{Mn}_{1.5} \mathrm{O}_{4}$ phases in which the transition-metal atoms are ordered and disordered, given the elemental contrast neutrons are easily able to. It is also convenient that ${ }^{6} \mathrm{Li}$ (which has a high neutron absorption) can be replaced by ${ }^{7} \mathrm{Li}$, which does not, giving the possibility to enhance the diffraction signal if necessary.

Second, neutron-scattering cross sections are, in general, quite small, so neutrons are relatively penetrating and measurement occurs for the bulk of the sample. This penetration enables the composition of electrodes to be easily measured in an operating battery.

These advantages are so significant for battery materials that dedicated neutron powder diffractometers, such as the SPICA $^{[17]}$ instrument at the Material and Life Science Facility of 
the Japan Proton Accelerator Research Complex (J-PARC), have been developed. The instrument is optimized specifically for in situ measurements to clarify structural changes of battery materials. A recent review on neutron sources around the world and some examples of these sources being used to probe chemical reactions can be found in the references. ${ }^{[18]}$

NPD can be used to determine the crystallographic positions of the charge-carrying lithium ions, atomic displacement parameters, and occupancies. Importantly, the high penetration of neutrons allows these to be determined from within a whole, commercial-sized battery and, coupled with the fastdetection ability of modern instrumentation, enables NPD to probe, in real-time, the bulk crystallographic changes of electrodes in functioning batteries through operando studies, which are important in elucidating charge-carrying ion-insertion/-extraction mechanisms. Despite these advantages, NPD is still used only a fraction as frequently as XRPD in the study of battery materials, mostly due to the requirement for a central facility and associated logistics, but also because even the most powerful neutron beams are weak compared with photon beams, so the samples and counting times for neutrons are correspondingly greater. Consequently, neutron scattering is rarely used when the desired information can be obtained by another means.

Typically, a large range of operating variables are examined during the electrochemical performance testing of batteries, starting with conventional charge-discharge cycling at a fixed current rate alongside cyclic voltammetry, and then moving to examine variable current rates and cutoff voltages, to name a few. The entire gamut of such variables cannot be performed in situ, predominantly due to X-ray and neutron scattering instrument time constraints. One approach taken is to explore electrochemical parameter space (e.g., electrochemical conditions during electrode testing) ex situ and to select the electrochemical conditions that produce interesting performance for in situ structural studies.

\section{Overview of Cells and Experimental Setup Requirements}

The objectives of an operando experiment are to obtain a high-quality signal from the electrode of interest while it is inside a whole commercially equivalent battery, that is, one that can be commercially used, and to collect data while the battery is being charged/discharged. The data should be collected with a high temporal resolution, that is, in sufficient time steps, so as to not smear or miss any structural transitions, with this being increasingly important at faster charge/ discharge rates. There is often a compromise between the time required to collect data, the current rate that can be applied to the electrode/battery, and the time available on instruments.

In these experiments, the whole battery is exposed and thus every component can contribute to the signal. Therefore, it is essential to carefully select the components of the battery and to modify these as necessary to minimize their contribution to the data, or move their signal away from reflections from the electrode of interest, for example, by swapping copper current collectors with aluminum in sodium-ion batteries if the copper reflections overlap with the electrode under study.

If sufficiently strong and well-resolved signals are collected from the electrode of interest, then structural analysis can be performed. A typical first step in data analysis is single-peak fitting, but ultimately full structural refinements can be performed, which may lead to the identification of new or unknown phases. In addition, accurate atomic parameters can be determined, such as lithium and sodium atomic parameters, in electrodes for each diffraction pattern collected during the charge/discharge process. Determining atomic parameters is the most difficult aspect of this work and is often not achieved. The structural changes that can be determined are described in Section 3.1; these give atomic-level insight into battery function.

Battery geometry can significantly impact data quality. In particular, with absorption effects, a relatively equal incident and scattered radiation path length at every angle is required for accurate peak intensities and simplified data analysis. Introduction of an angular-dependent attenuation by the sample geometry, often in combination with that of the instrument, is detrimental to the level of structural detail that can be obtained. This is because the peak intensities are no longer representative of only the electrode structure, but also include an angle-dependent attenuation factor in addition to the structure. Although a homogeneous and annular sample is ideal from this perspective, the quality of the signal is redundant if the cell does not function well electrochemically.

A key concept in the design of cells for these in situ experiments is the condition that the electrochemical behavior of the materials under study is as close as possible to that in a conventional device, for example, a coin, pouch, or cylindrical cell. Importantly, the charge-discharge curves measured during the in situ experiment should reproduce the expected features of the conventional cells for a direct comparison of collected diffraction data with performance. It is well established that some in situ cell designs affect performance, and these effects must be understood to link performance with structure and phase evolution. This may involve linking structural evolution within the cell-type rather than a general behavior of the electrode. Commercial cells have a clear advantage to specialist in situ cells in this regard because the diffraction data can be directly linked to well-characterized performance.

Typically, every effort is made such that specialist in situ experimental cells enable the material under study to perform as close as possible to that in conventional cells. However, when conducting in situ NPD experiments, the presence of hydrogen can present an insurmountable barrier to obtaining meaningful information due to hydrogen's large incoherent neutron scattering cross section, which results in a large background in the data. Specialist NPD cells are therefore developed with deuterated electrolytes (in which the isotopic substitution of hydrogen with deuterium reduces significantly the background) and hydrogen-rich separators are replaced with hydrogen-poorer separators. ${ }^{[19]}$ Deuterated electrolytes are known to significant- 
ly affect cell performance, which is typically reduced as a consequence of the diffusion mechanisms being altered by heavier deuterium, and consequently, affecting the operating voltage window. In these cases, the electrochemical performance is extensively characterized and understood in ex situ experiments, so that information gained can be confidently correlated to performance.

\subsection{Battery designs for in situ NPD experiments}

To date, only 38 papers have been published that are related to the use of in situ NPD to investigate lithium-ion batteries, probably due to limited access to neutron facilities, difficulty of preparing neutron-friendly batteries, and often-complex data analysis. Advances in neutron instrumentation and the increased attention and value gained by researchers using in situ NPD to study batteries have meant that the number of publications has dramatically increased since 2012. Figure 3 shows the number of publications in every calendar year and Table 1 summarizes the studied materials and type of batteries used in the in situ NPD experiments. In this section, we review the battery designs and battery types used in in situ NPD experiments.

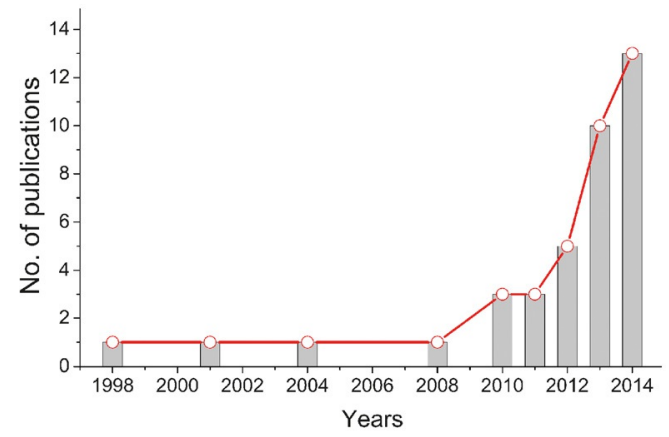

Figure 3. Statistics of publications reporting in situ NPD studies of lithiumion batteries.

\begin{tabular}{|c|c|c|c|c|}
\hline Year & Material studied & Cell configuration & Battery type & Reference \\
\hline 1998 & $\mathrm{Li}_{x} \mathrm{Mn}_{2} \mathrm{O}_{4}$ & half & Pyrex tube-like & [20] \\
\hline 2001 & $\mathrm{LiMn}_{2} \mathrm{O}_{4}$ & half & Pyrex tube-like & [21] \\
\hline 2004 & $\mathrm{LiCoO}_{2}$ and graphite & full & commercial 18650-type & [22] \\
\hline 2008 & $\mathrm{LiNiO}_{2}$ & half & PEEK large coin-type & [23] \\
\hline 2010 & $\mathrm{Li}_{4} \mathrm{TT}_{5} \mathrm{O}_{12}$ & half & PEEK large coin-type & [7a] \\
\hline 2010 & $\mathrm{LiFePO}_{4}$ and graphite & full & commercial 18650-type & [24] \\
\hline 2010 & $\mathrm{LiCoO}_{2}$ and graphite & full & commercial 18650-type & {$[5 a]$} \\
\hline 2011 & $\mathrm{Li}_{4} \mathrm{Ti}_{5} \mathrm{O}_{12}$ and $\mathrm{TiO}_{2}$ & half & roll-over cylindrical V & [11] \\
\hline 2011 & $\mathrm{MoS}_{2}$ & half & roll-over cylindrical V & [15] \\
\hline 2011 & $\mathrm{Li}\left(\mathrm{Co}_{0.16} \mathrm{Mn}_{1.84}\right) \mathrm{O}_{4}$ & half & roll-over cylindrical V & [25] \\
\hline 2012 & $\mathrm{LiCoO}_{2}$ and graphite & full & commercial 18650-type & [26] \\
\hline 2012 & $\mathrm{LiCoO}_{2}$ and graphite & full & commercial 18650-type & [27] \\
\hline 2012 & $\mathrm{LiFePO}_{4}$ & half & roll-over cylindrical V & [28] \\
\hline 2012 & $\mathrm{LiCoO}_{2}, \mathrm{LiMn}_{2} \mathrm{O}_{4}, \mathrm{LiFePO}{ }_{4}$, graphite, $\mathrm{Y}\left[\mathrm{Fe}(\mathrm{CN})_{6}\right]$, and $\mathrm{Fe}\left[\mathrm{Fe}(\mathrm{CN})_{6}\right]$ & half & roll-over cylindrical V & [29] \\
\hline 2012 & graphite & full & commercial 18650-type & [30] \\
\hline 2013 & $\mathrm{LiFePO}_{4}$ and $\mathrm{Li}_{1} \mathrm{Mn}_{19} \mathrm{O}_{4}$ & half & $\mathrm{Ti}-\mathrm{Zn}$ alloy large coin-type & [31] \\
\hline 2013 & $\mathrm{LiMn}_{2} \mathrm{O}_{4}$ and graphite & full & commerical pouch-type & [32] \\
\hline 2013 & $\mathrm{Li}_{1.1}\left(\mathrm{Ni}_{1 / 3} \mathrm{Mn}_{1 / 3} \mathrm{Co}_{1 / 3}\right)_{0.9} \mathrm{O}_{2}, \mathrm{LiFePO}_{4}, \mathrm{Li}_{4} \mathrm{Ti}_{5} \mathrm{O}_{12}$, and graphite & half & Al-Ti alloy large coin-type & [33] \\
\hline 2013 & V-doped LiFePO & full & commerical pouch-type & [34] \\
\hline 2013 & $x \mathrm{Li}_{2} \mathrm{MnO}_{3} \cdot(1-x) \mathrm{LiMO}_{2}$ composite & full & single-stack pouch-type & [35] \\
\hline 2013 & $\mathrm{LiFePO}_{4}$ & half & roll-over cylindrical Swagelock-type & [36] \\
\hline 2013 & graphite & full & commercial 18650-type & [37] \\
\hline 2013 & graphite & full & commercial 18650-type & [5c] \\
\hline 2013 & graphite & full & commercial 18650-type & [13] \\
\hline 2013 & $\mathrm{Li}_{1+\mathrm{y}} \mathrm{Mn}_{2} \mathrm{O}_{4}$ & full & pouch-type & [38] \\
\hline 2014 & $\mathrm{LiFePO}_{4}$ & full & commercial pouch-type & [39] \\
\hline 2014 & $\mathrm{Li}\left(\mathrm{Ni}_{1 / 3} \mathrm{Mn}_{1 / 3} \mathrm{Co}_{1 / 3}\right) \mathrm{O}_{2}$ & full & commercial 18650-type & [40] \\
\hline 2014 & $\mathrm{Li}_{4} \mathrm{Ti}_{5} \mathrm{O}_{12}$ & full & pouch-type & [41] \\
\hline 2014 & $\mathrm{LiNi}_{0.5} \mathrm{Mn}_{1.5} \mathrm{O}_{4}$ and $\mathrm{Li}_{4} \mathrm{Ti}_{5} \mathrm{O}_{12}$ & full & pouch-type & [42] \\
\hline 2014 & $\mathrm{LiCoO}_{2}$ and graphite & full & commercial 18650-type & [43] \\
\hline 2014 & graphite & full & commercial 18650-type & [44] \\
\hline 2014 & $\mathrm{Li}\left(\mathrm{Ni}_{1 / 3} \mathrm{Mn}_{1 / 3} \mathrm{Co}_{1 / 3}\right) \mathrm{O}_{2}$ and Al-doped Li $\left(\mathrm{Ni}_{1 / 2} \mathrm{Co}_{1 / 2}\right) \mathrm{O}_{2}$ & full & commercial 18650-type & [45] \\
\hline 2014 & $\mathrm{Li}_{4} \mathrm{Ti}_{5} \mathrm{O}_{12}$ & full & pouch-type & [46] \\
\hline 2014 & $\mathrm{LiCoO}_{2}, \mathrm{LiMn}_{2} \mathrm{O}_{4}$, and graphite & full & planar coin-type with Si case & [47] \\
\hline 2014 & $\mathrm{Li}\left(\mathrm{Ni}_{1 / 3} \mathrm{Mn}_{1 / 3} \mathrm{Co}_{1 / 3}\right) \mathrm{O}_{2}$ and Al-doped Li $\left(\mathrm{Ni}_{1 / 2} \mathrm{Co}_{1 / 2}\right) \mathrm{O}_{2}$ & full & commercial 18650-type & [48] \\
\hline 2014 & $\mathrm{Li}\left(\mathrm{Ni}_{1 / 3} \mathrm{Mn}_{1 / 3} \mathrm{Fe}_{1 / 3}\right) \mathrm{O}_{2}$ & full & pouch-type & [49] \\
\hline 2014 & $\mathrm{Li}_{0.18} \mathrm{Sr}_{0.66} \mathrm{Ti}_{0.5} \mathrm{Nb}_{0.5} \mathrm{O}_{3}$ & half & roll-over cylindrical V & [50] \\
\hline 2014 & $\mathrm{Li}_{1+x} \mathrm{Mn}_{2-x} \mathrm{O}_{4}, x=0,0.05,0.10$ & half & Ti-Zn alloy large coin-type & [51] \\
\hline 2015 & graphite & full & commercial 18650-type & [52] \\
\hline 2015 & $\mathrm{LiNi}_{0.5} \mathrm{Mn}_{1.5} \mathrm{O}_{4}$ and $\mathrm{Li}_{4} \mathrm{Ti}_{5} \mathrm{O}_{12}$ & full & pouch-type & [53] \\
\hline
\end{tabular}




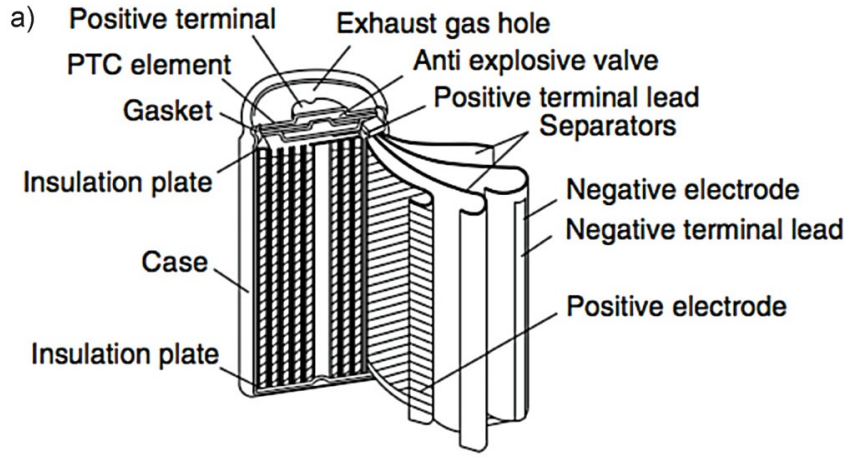

b)

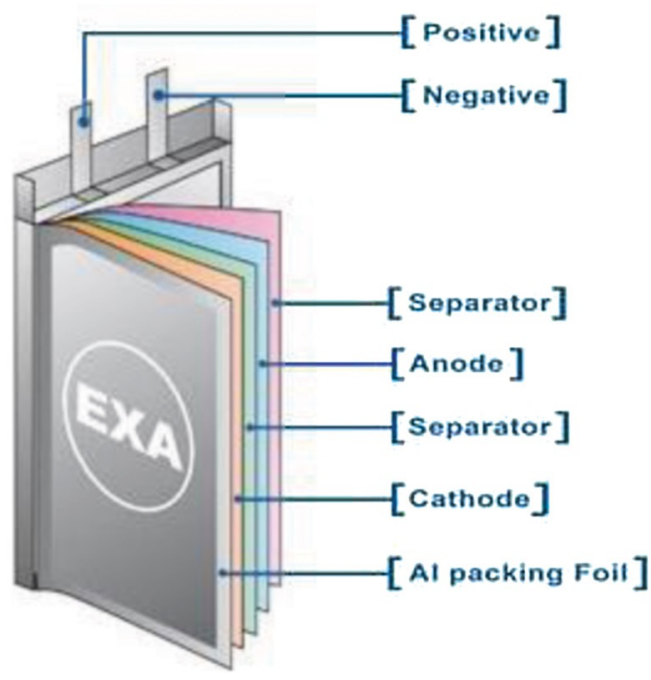

Figure 4. Schematic illustration of commercial a) cylindrical (Panasonic.com) and b) pouch-type (Mpoweruk.com) batteries. PTC=positive temperature coefficient.

Nowadays, commercial batteries are mostly packed in two different arrangements: cylindrical (i.e., 18650 battery) and pouch-/prism-type cells containing layered sheets (Figure 4). Both packing arrangements have the same aim: minimize the battery volume. Cylindrical batteries contain a roll-over cathode-separator-anode-separator that is wound with a cathode lead (center tube) such that it is dense and compact. The outer casing is designed to be strong and protects the battery from deformation, caused by physical damage, or decomposition of the inner electrolyte during cycling. However, the metal casing also limits the battery size (in terms of Ah) by constraining the maximum amount of cathode and anode, for example, only about $3 \mathrm{Ah}$ is achieved in a typical 18650 battery with existing commercial cathode materials. On the other hand, pouch/prism layered batteries contain multiple sheets of cathode-separator-anode layers that are assembled and encased in a soft laminated aluminum foil or harder casing as required. The flexibility of the pouch battery, in terms of size, capacity (ranging from 0.5 to $90 \mathrm{Ah}$ and above), shape, and so forth, is high, which makes this type of battery favorable and easier to fit into integrated battery packs for high-power energy applications, that is, electric vehicles. In an in situ NPD experiment, commercial batteries are nearly always preferred because of the high content of active material (i.e., $>15 \mathrm{~g}$ in 3 Ah battery with $\mathrm{LiCoO}_{2}$ or $\mathrm{LiMnNiCoO}_{2}$ (NMC) cathodes); the main draw- backs are the limited options of cathode and anode chemistries. Despite the high penetration of neutrons, the battery geometry, as well as the composition of the non-electrode battery components, must be considered in an in situ NPD experiment. ${ }^{[5 a, c, 13,22,24,26,27,30,34,37,43-45,48]}$ The hydrogen content of the battery is also detrimental to the quality of NPD data. Hydrogen produces a background component in NPD data due to its large incoherent neutron-scattering cross section, and ideally cells should not contain hydrogen. Commercial batteries overcome this issue through their large electrode contents, which makes the ratio of electrode to hydrogen sufficient for the collection of high-quality NPD data.

Custom-designed, neutron-friendly batteries that can employ developing or commercial electrode materials as the cathode and anode for in situ NPD experiments have evolved. The very first lithium-ion battery used in an in situ NPD experiment was a binder-free pseudo-solid-state battery. It had a half-cell configuration with a cylindrical shape that used a Pyrex tube as the casing material, lithium roll as the anode, Celgard separator, cathode composite (mixture of active material, electrolyte, and carbon black), and gold plating on the inner wall of the tube as the cathode current collector. The cathode was loosely packed, and thus, had poor contact with the current collector. Given the high amount of active material, the detected signals were excellent. However, the design of the battery made the electrochemical performance of the cathode under study far from that normally achieved. This design was used by the groups of Bergstrom ${ }^{[20]}$ and Berg, ${ }^{[21]}$ and is shown in Figure 5 with the corresponding NPD data.

Learning from this design to improve electrochemical performance, cells with compactly packed electrodes as a result of mechanical force were constructed. Four alternate designs have been explored in in situ NPD experiments, as shown in Figure 6. The electrochemical performance of these batteries is generally satisfactory, whereas the collection time of each operando pattern is typically quite long (30 $\mathrm{min}$ or more). Moreover, these designs require a premade cell body that may not be convenient to handle in some laboratories.

Another successfully implemented design is the so-called roll-over design first introduced in Sharma et al. ${ }^{[11,15]}$ This design is a modified version of the original cylindrical cell (i.e., 18650) and has been used reliably to correlate the structure and electrochemistry of electrode materials. The central part of the battery is prepared by rolling over the stack, which is composed of a long strip of separator, positive electrode with the slurry facing up and aluminum rod (or copper wire) wound in the "tab" at one end, the second strip of separator, and finally the lithium metal with copper wire wound in the end of the lithium metal (the same end as the aluminum rod, see Figure 7). The assembly is done inside a glove box. The rolled stack is then inserted into a vanadium can, which contributes almost negligibly to the NPD pattern. Although the roll-over battery has produced excellent results when using in situ NPD, a significant drawback of the design is the technical degree of difficulty in its construction, with compactness of the roll-over difficult to achieve and failed cells often leading to limited rate capability and capacity. Short circuits and disconnects are rela- 
a)

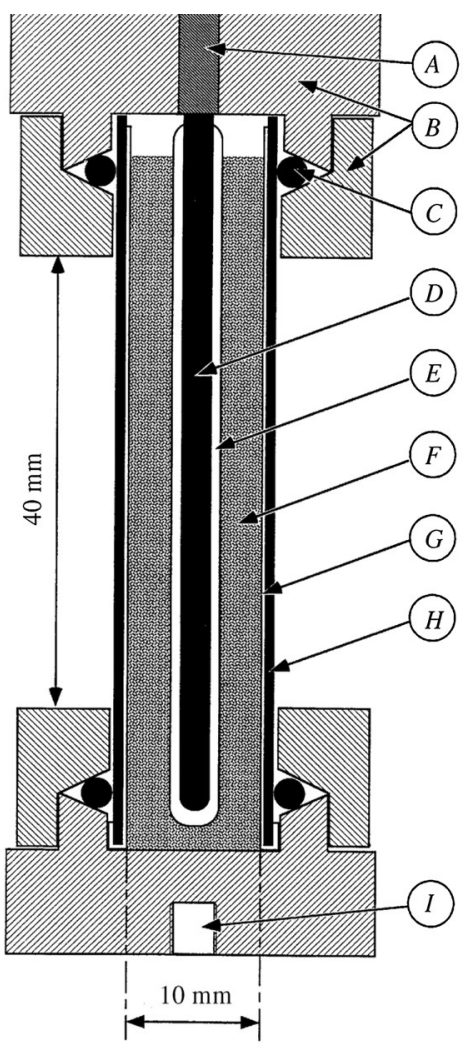

b)

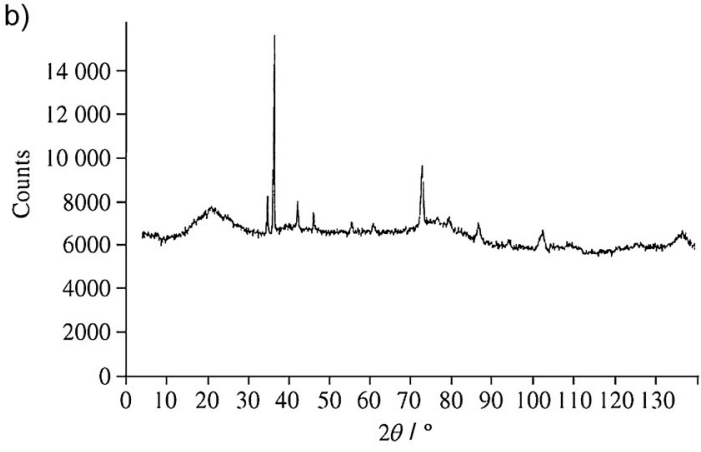

c)

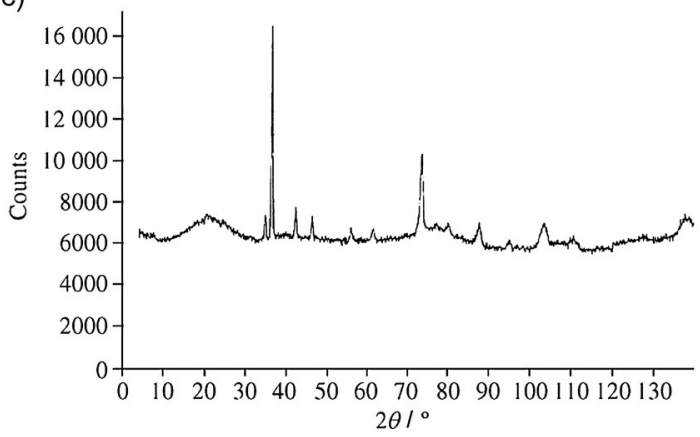

Figure 5. The binder-free pseudo-solid-state battery (a) and corresponding NPD patterns of the battery in the b) charged and c) discharged states. ${ }^{[2]}$ Reproduced with permission from IUCr. A = seal for lithium, $B=$ brass collars, $\mathrm{C}=\mathrm{O}$-ring, $\mathrm{D}=$ lithium, $\mathrm{E}=$ solid polymer electrolyte and separator, $\mathrm{F}=$ cathode mixture, $\mathrm{G}=$ gold current collector, $\mathrm{H}=$ Pyrex tube, $\mathrm{I}=$ connection to diffractometer.

tively easy to introduce into the roll-over design, and these can be catastrophic to battery function and are detectable only once the expensive deuterated electrolyte has been added. Applying sufficient pressure to the rolled electrodes is particularly difficult when winding the cell by hand. The process requires manual dexterity inside a glove box and may not lead to consistent results. Moreover, the total mass of active material with respect to all cell components is dependent on the size of the vanadium can and must be recorded to calculate the total neutron absorption. Finally, the size of the can and thickness of the separator (i.e., polyvinylidene fluoride (PVDF) membrane) constrain the amount of active material, and the battery is in the half-cell configuration with a large amount of lithium foil (similar volume as the target working electrodes), which can be hazardous.

The last cell design, which is now becoming more popular and is relatively easy to prepare in a standard laboratory, is the pouch cell, which contains sheets of multiple individual cells connected in parallel or rolled similarly to the commercial pouch-type batteries found in mobile electronics. The battery is prepared by stacking anode-separator-cathode layers in parallel (Figure $8 \mathrm{a}$ ). The stack is tightened with Kapton tape (Figure $8 b$ ) and the assembly can be done outside of the glove box because the battery can be used in the full-cell configuration. However, the electrode stack needs to be placed in an argon-filled glove box to dry for at least $24 \mathrm{~h}$ before the electrolyte is injected. The stack is then wrapped in a polypropylene-coated aluminum pouch (Figure $8 \mathrm{c}$ ) and heat-sealed, with one side left open for the injection of the electrolyte. The typical thickness of a battery is about $0.6-0.8 \mathrm{~cm}$, including the separator, electrodes, and aluminum pouch casing. The pouch casing is aluminum foil about $0.16 \mathrm{~mm}$ thick with the outer surface coated with thin polyamide and the inner surface coated with thin polyester. The polyamide/aluminum/polyester contains hydrogen, and the contribution of these components to the NPD data is not negligible. The inner polyester layer is used for heat sealing and protecting the electrode stack from short circuits. The outer polyamide layer can be removed by light sanding, which reduces the amount of hydrogen in the sample. The stacked cell resembles a rectangular prism (or pouch) that can typically function at higher charge/discharge rates. The disadvantages of the pouch-type battery for in situ NPD experiments are similar to those of the 18650-type, in addition to a further complication arising from its non-annular geometry; the latter can be addressed by aligning the sample on the instrument, so that the battery volume probed by the neutrons has equal width and thickness, which simulates an annular sample. Predominantly due to its ease of construction in a research-laboratory setting, the pouch-type battery is increasingly being used in NPD experiments.

\subsection{Battery designs for in situ SXRPD experiments}

Compared with the battery designs used for NPD experiments, the batteries employed in in situ XRPD or SXRPD are relatively simpler and smaller. A recent review of these designs has been published, ${ }^{[54]}$ in which cells for laboratory and synchrotron XRD experiments are compared and the use of reflection and transmission geometry are discussed. Considering transmission 

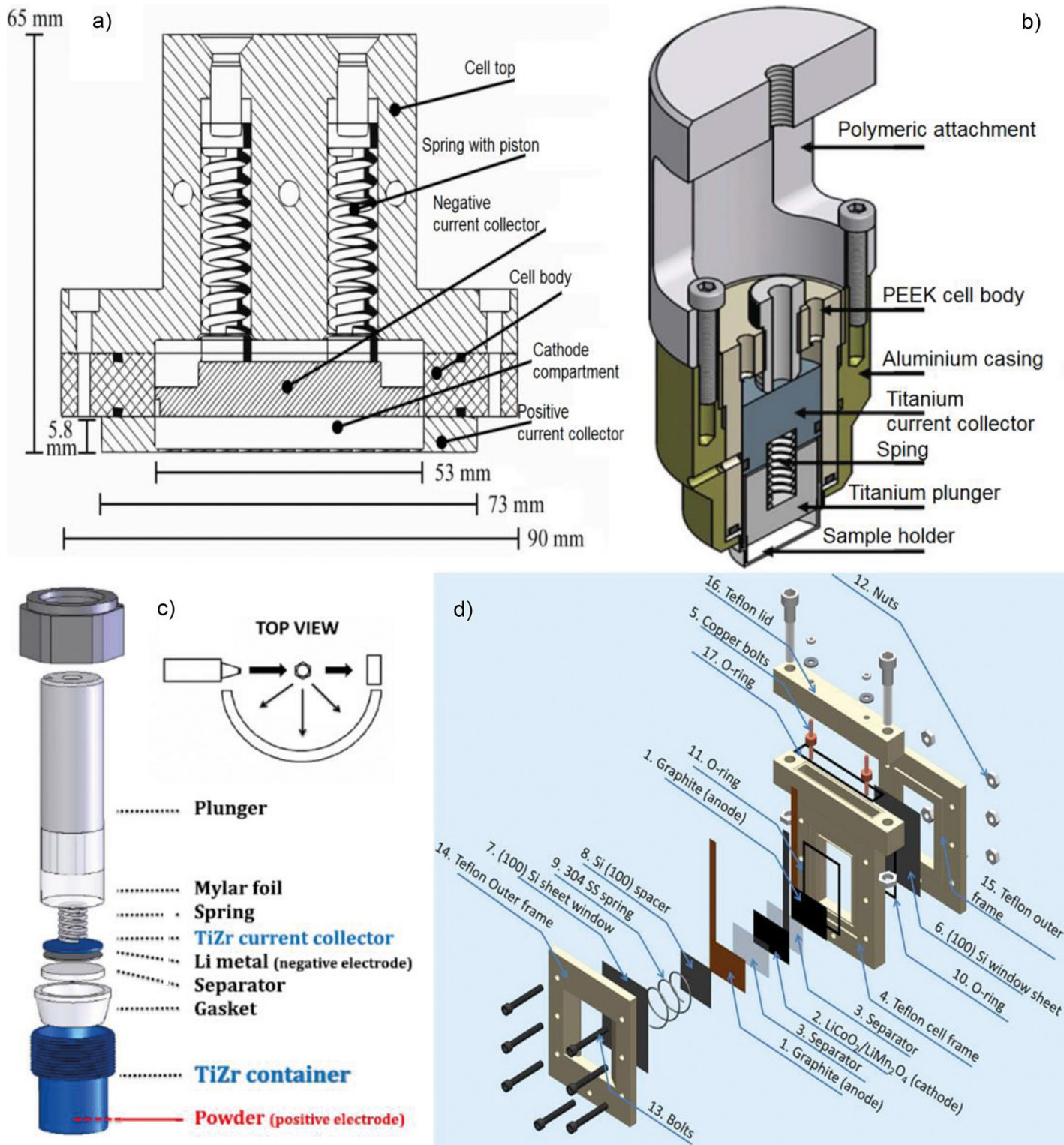

Figure 6. The battery designs presented by a) Rosciano et al.. ${ }^{[23]}$ b) Godbole et al., ${ }^{[33]}$ c) Bianchini et al., ${ }^{[31]}$ and d) Vadlamani et al. ${ }^{[47]}$ These figures have been reproduced from Ref. [33] with permission from The Royal Society of Chemistry, IUCr, and reprinted with permission from Refs. [31,47]. Copyright 2013 and 2014, The Electrochemical Society.

XRPD experiments, the batteries are designed with a thin lithium-/sodium-metal anode, polymer separators, and carbonate electrolytes to minimize X-ray absorption. They feature holes in the stainless-steel casing material to allow X-ray transmission and these holes are covered with Kapton or beryllium windows, depending on the design. A commonly used battery for a transmission SXRPD experiment can be considered as a modified "coin-type" (i.e., CR2032) battery. Three types of transmission in situ cells for SXRPD experiments are compared herein: planar stacking, coin-type, and a specially designed Argonne multipurpose in situ X-ray (AMPIX) cell. The signals from all three battery types are comparable, but the electrochemical performance and cell preparation can be distinctly different.

Brant et al. ${ }^{[54]}$ showed that the planar stacking battery comprised of two aluminum plates: one with a small recess $(1.2 \times$
$1.2 \times 0.2 \mathrm{~cm}$ ) and the other with a raised section with slightly smaller dimensions. A hole was drilled on each plate to allow the transmission of the X-ray beam and each plate or casing was electrically insulated with Kapton tape. The whole cell was assembled as shown in Figure 9 with the beam direction specified. Each electrode was placed inside and isolated by using a PVDF separator. The aluminum plates or casings are also used as current collectors and the plates are held together by insulated screws. Kimpton and $\mathrm{Gu}^{[55]}$ among other authors, ${ }^{[56]}$ presented the use of a modified coin-cell (CR2032, see Figure 10) with open windows. It is a typical coin cell, but features holes in the casing to allow the $\mathrm{X}$-ray beam to pass through. Compared with the planar cell proposed in Brant et al., ${ }^{[54]}$ this design is feasible for preparation in most laboratories. However, in both cases, the main drawback is the Kapton- 

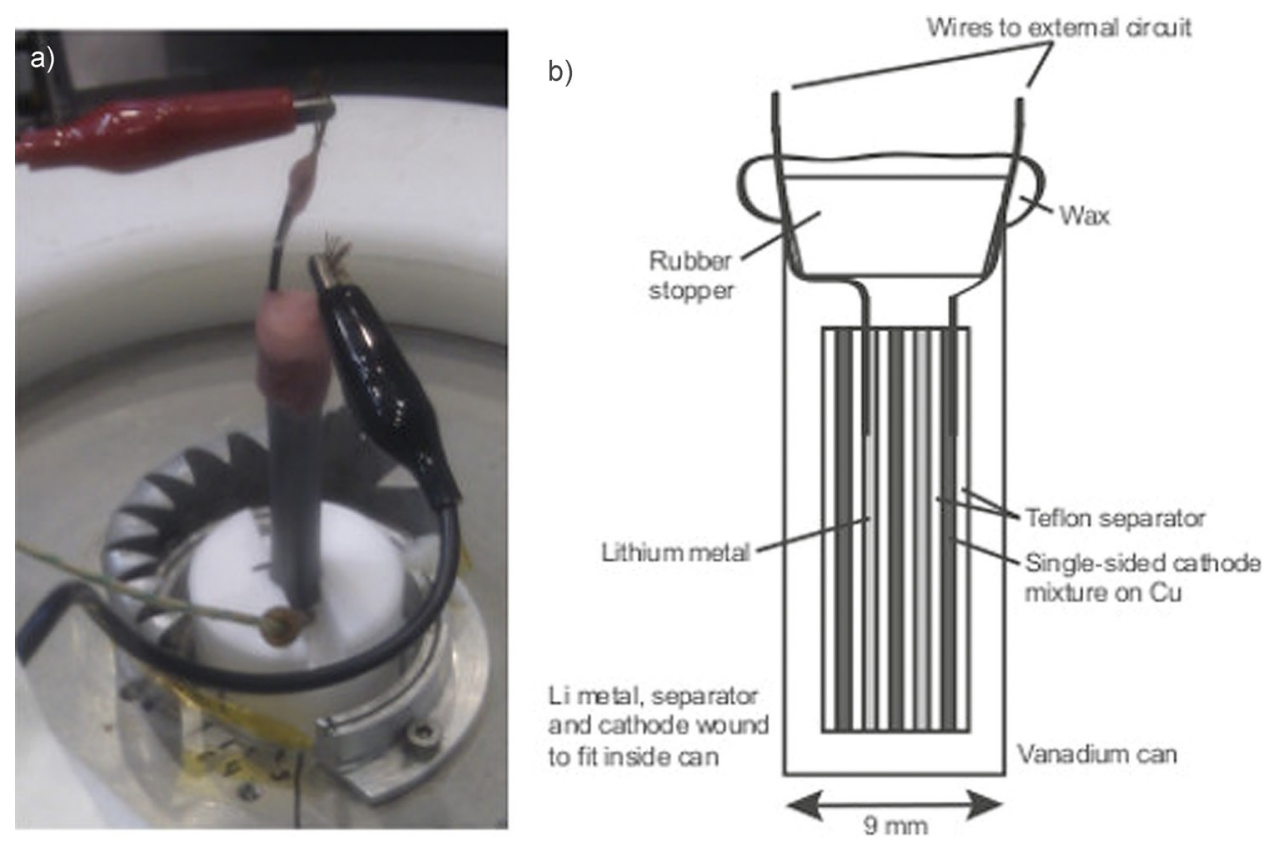

It is noteworthy that electrochemical cells have been designed specifically to overcome contact issues in previous laboratory or synchrotron XRPD cells. These include a Swagelok cell ${ }^{[57]}$ design for use in transmissiongeometry experiments in which the beam passes through the cell assembly and the lithium side of the battery is covered with an epoxy resin. The resin acts to seal lithium from air and behave as a poor X-ray scatter. A modification of this design ${ }^{[58]}$ uses beryllium windows on both the positive and negative sides of the battery to minimize further X-ray scattering. This design allows for both transmission and reflection geometries. A se-

Figure 7. The vanadium-can roll-over battery design presented in Brant et al. ${ }^{[50]}$ quence of plungers and springs

а)

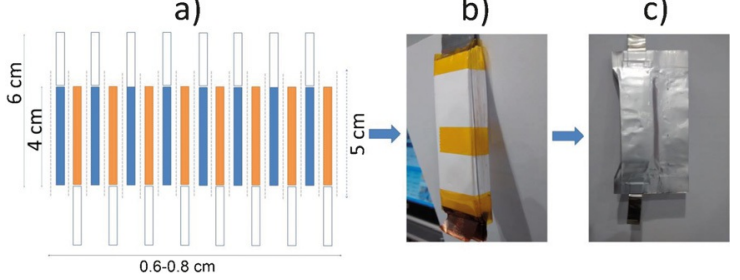

Figure 8. Stack-layered battery design with an aluminum casing, as reported by Pang and Peterson: ${ }^{[53]}$ a) a schematic layout of the stacked layers, b) a photograph of a) in practice, and c) the Al casing on the cell. Reproduced with permission from IUCr.

tape covered holes, which can limit the performance of the battery. Moreover, the Kapton-tape covered holes represent the volume that is sampled by the X-ray beam, and this data may show a less electrochemically active part of the cell (or one that lags) due to the relatively poor contact of the electrode underneath the holes to the casing current collector material.

To overcome the contact issue, the AMPIX (Figure 11$)^{[16]}$ cell was designed to provide reliable electrochemical cycling over extended periods owing to the uniform stack pressure applied by rigid X-ray windows and the formation of a high-fidelity hermetic seal. This design is thought to be versatile, easy to use, and suitable for operando and in situ measurements of battery materials during electrochemical cycling by using a variety of X-ray techniques. The rigid X-ray windows ensure the electrochemical performance of the battery, which allows penetration of the X-ray beam, and the researchers can connect phase evolution with the electrochemical behavior more accurately. The AMPIX cell is arguably one of the most successful and reliable designs; however, for the majority of researchers this is not as convenient to prepare as the coin-type cells.
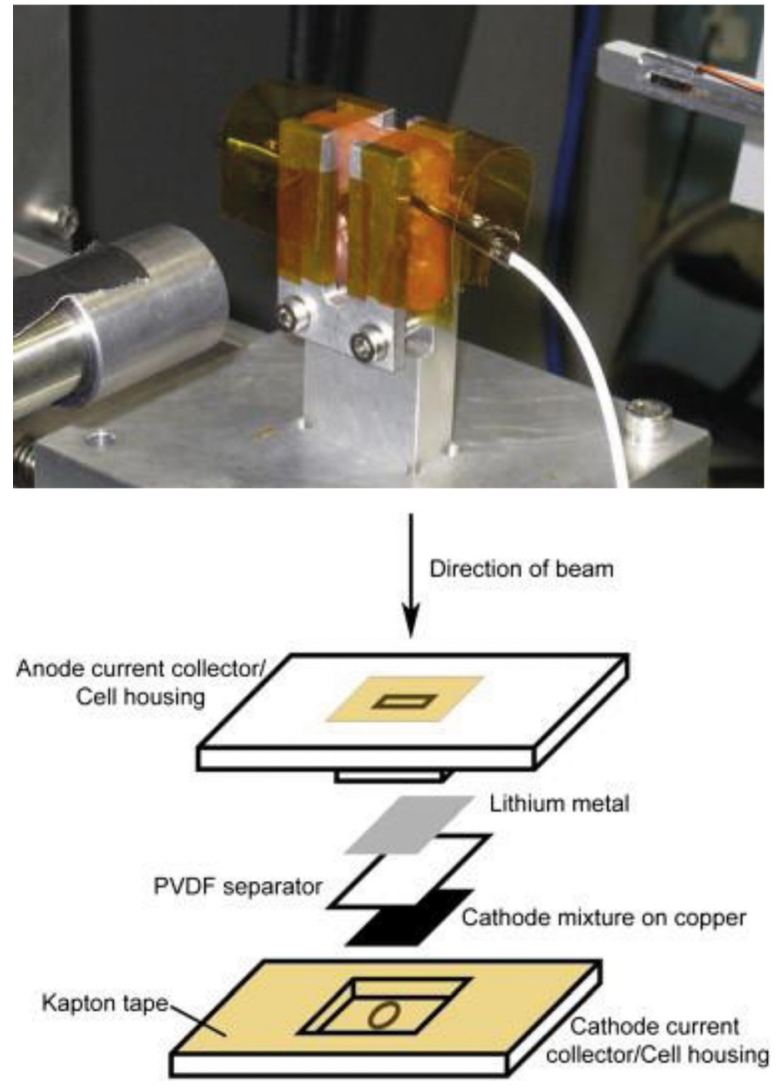

Figure 9. Planar coin cell for in situ synchrotron XRPD experiments reported by Brant et al. ${ }^{[54]}$

are used to ensure contact and the cell can be easily disassembled. Notably, the cell has been used at rates of $5 \mathrm{C}$ for at least 10 cycles and shown to work for both XRPD and X-ray absorp- 


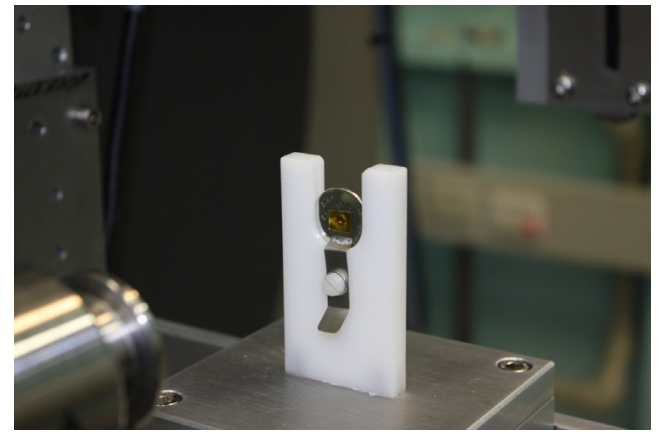

Figure 10. Coin cell with open windows for in situ synchrotron XRPD experiments similar to those presented by Kimpton and Gu. ${ }^{[55]}$
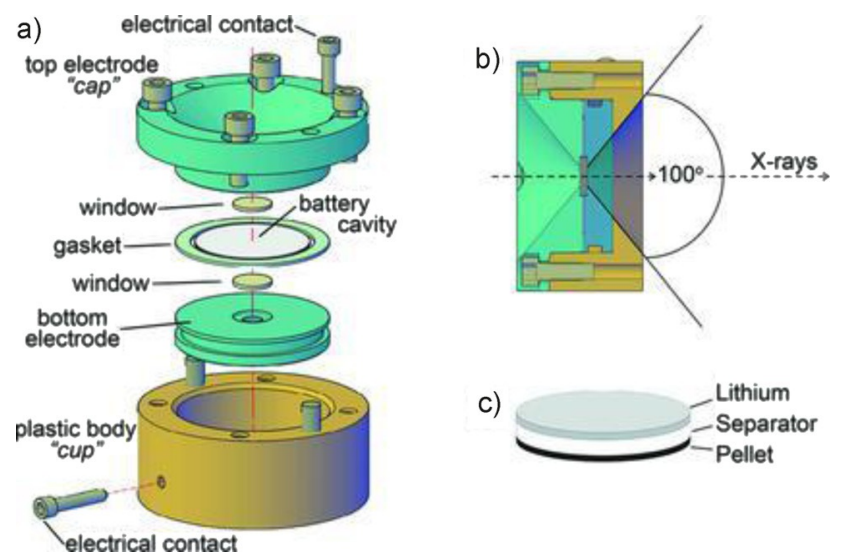

e)

Figure 11. The AMPIX cell for in situ SXRPD experiments reported by Borkiewicz et al. ${ }^{[16]}$ Reproduced with permission from IUCr.

tion spectroscopy experiments. Recently, a design for laboratory XRPD experiments was developed and, although complex, it is reliable and robust. ${ }^{[59]}$ The main advantage of this cell is the replacement of beryllium with a graphite cell window, which makes it safer to handle. It features a graphite dome with a conventional coin-cell assembly. Screws are used to tighten the cell stack to ensure contact and XRPD patterns have been recorded in $18 \mathrm{~min}$ with the cell. One foreseeable issue may be electrolyte containment; however, this may be overcome with electrolyte-poor cells.

The choice of cell to use in XRPD experiments ultimately depends on the instrument and type of information that is required, for example, the desired current rate. The important parameter in the choice of the cell is that the electrochemical performance of the in situ XRPD cell is equivalent to that of a conventional cell.

\section{Key Examples}

\subsection{Alkaline batteries}

Alkaline batteries find use in many portable applications with low power requirements, such as tape recorders, cassette players, and wall clocks. Arguably these batteries are superseded by rechargeable $\mathrm{NiMH}$ or lithium-ion batteries for certain appli-
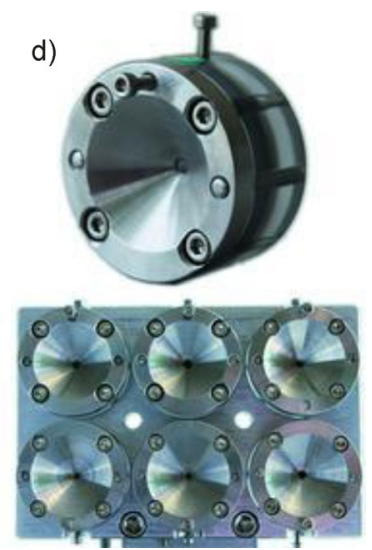

cations, such as portable music players, yet they are still widely available and used for certain applications due to their significantly lower cost. Alkaline batteries have largely replaced zinccarbon batteries, but these represent one of the cheapest batteries on the market. In the case of zinc-carbon batteries, $\mathrm{Zn}$ is the anode with $\mathrm{MnO}_{2}$ coated on a carbon cathode, which transforms into $\mathrm{Mn}_{2} \mathrm{O}_{3}$ during discharge. The electrolyte is an aqueous solution of $\mathrm{NH}_{4} \mathrm{Cl}$ or $\mathrm{ZnCl}_{2}$ in the form of a paste. Comparatively, the commercial alkaline batteries contain the same materials for the anode and cathode, but the electrolyte is conventionally $\mathrm{KOH}_{(\mathrm{aq})}$. An excellent account of polymorphism in $\mathrm{MnO}_{2}$ and the development of perceived reduction reactions in alkaline batteries can be found in the literature. ${ }^{[60]}$ In situ NPD work $^{[60,61]}$ to study the electrochemistry of $\gamma-\mathrm{MnO}_{2}$ was undertaken by using a specially designed cell with a deuterated electrolyte solution (KOD in $\left.\mathrm{D}_{2} \mathrm{O}\right)$, as shown in Figure 12. The $\gamma$-form of $\mathrm{MnO}_{2}$ is widely used in primary batteries. ${ }^{[62]}$ The in situ NPD study determined that the reduction process followed three stages and the final stage was responsible for the breakdown of the structure. Furthermore, thermally induced transitions were found to go through seven steps before transforming into $\alpha-\mathrm{Mn}_{2} \mathrm{O}_{3}$. Readers are also directed to a Ref. [63], which describes a neutron diffraction study of an alkaline battery by using the D1B diffractometer at the ILL in France.

In situ NPD data shows the transitions that occur within a cathode during discharge. Importantly, it is in the final stages of discharge that the structural breakdown of the cathode occurs and this is responsible for the completion of battery discharge, with the potential dropping to around zero after the final discharge stage. Here, the link between the cathode structure and electrochemical discharge curve suggests that a longer preservation of the structure may enable longer discharge; however, other variables of the battery need to be considered for this to occur. This deeper understanding of the discharge process in the cathode sheds light on how battery capacity may be improved.

\subsection{NiMH batteries}

$\mathrm{NiMH}$ batteries have been studied with neutron scattering techniques by substituting hydrogen with deuterium and exploring the relationship between battery performance and the structure of the constituents. NiMH batteries contain anodes based on the $\mathrm{LaNi}_{5}$ alloy, in which $\mathrm{Ni}$ can be substituted by transition metals and La is often a combination of rare-earth elements referred to as a mishmetal. These anodes replace the $\mathrm{Cd}$ anode found in $\mathrm{Ni}-\mathrm{Cd}$ batteries, making them significantly 

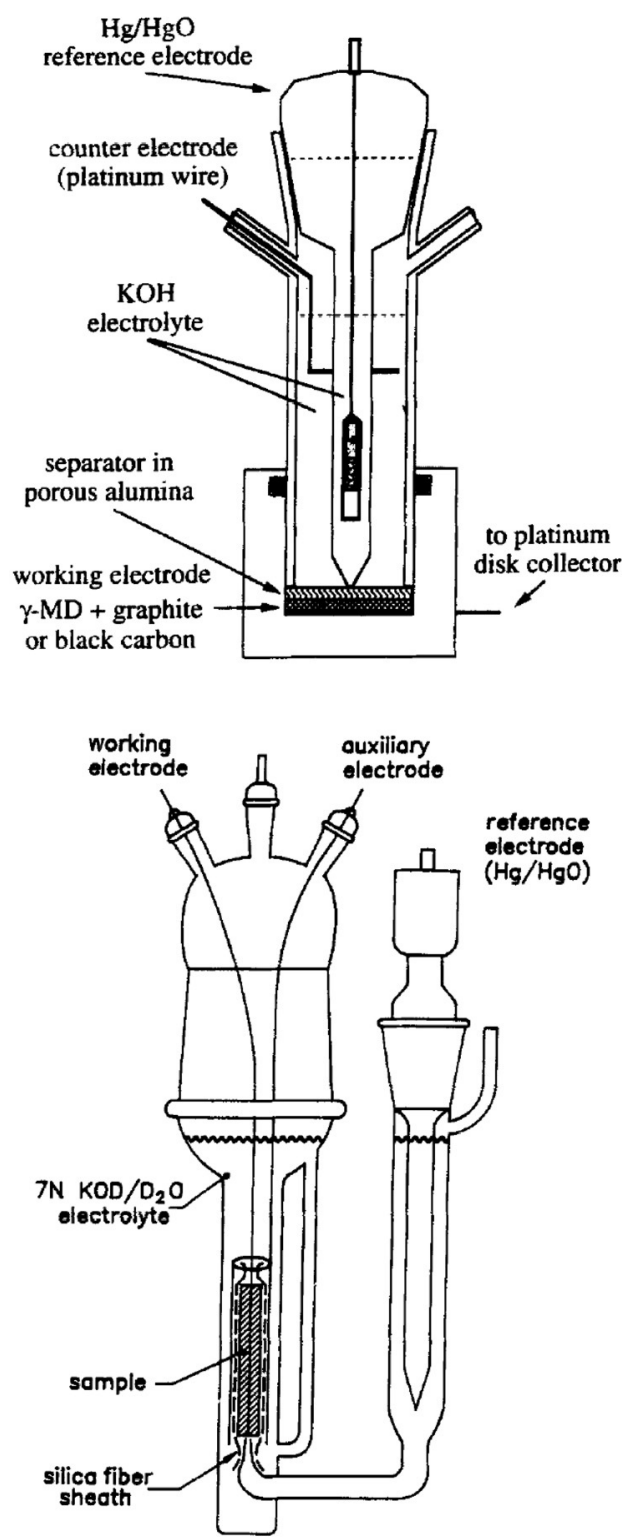

Figure 12. Schematic illustration of the cell used to demonstrate the function of an alkaline cell with in situ NPD. ${ }^{[60]}$

more environmentally friendly. ${ }^{[64]}$ Substitutions in the $\mathrm{LaNi}_{5}$ alloy are tailored to produce the best battery performance, in particular, cycle life and rate capability, which are the major drawbacks of these batteries. The electrolyte is $\mathrm{KOH}$ dissolved in water and the reduction of water or hydrogen gas dissociation is the means by which energy is stored. ${ }^{[65]}$ The battery chemistry can be written as $\mathrm{NiOOH} / \mathrm{Ni}(\mathrm{OH})_{2}|\mathrm{KOH}| \mathrm{AB}_{5} / \mathrm{AB}_{5} \mathrm{H}_{x}^{[66]}$ and we discuss the electrodes below.

A number of in situ NPD studies have been undertaken ${ }^{[65,67]}$ with custom-designed cells (Figure 13). Depending on neutron diffractometer collection times, different aspects of NiMH batteries have been investigated, for example, high current rate electrode behavior with the more intense D20 diffractometer relative to the moderate to low current rate behavior at the lower neutron-intensity instrument D1B (also at the ILL). Sufficient time resolution is critical to investigate high-current

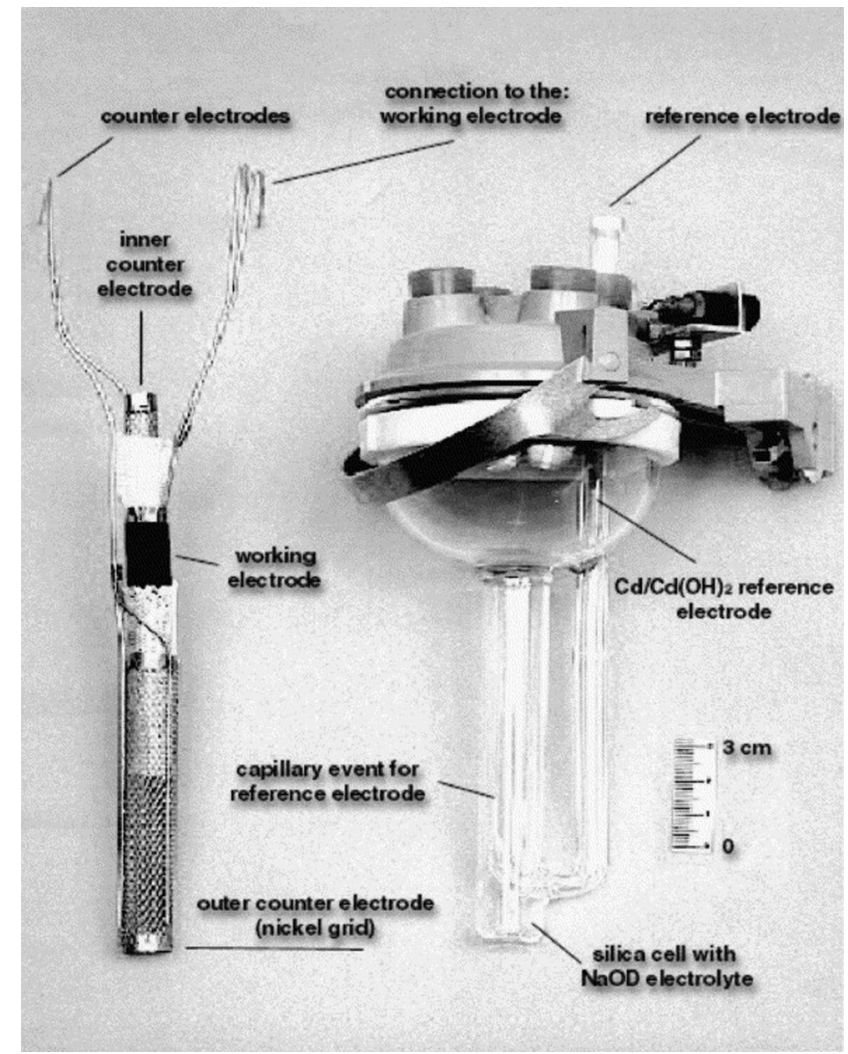

Figure 13. An in situ electrochemical cell for studying electrode evolution in a NiMH battery during operation. ${ }^{[65,67 a-e]}$

work, for example, $1 \mathrm{~min}$ acquisitions are required if the entire charge-discharge process is only $1 \mathrm{~h}$ long. In these cases, the electrolyte had to be deuterated $\left(\mathrm{KOD} / \mathrm{D}_{2} \mathrm{O}\right)$ to measure a signal from the electrode of interest and $2-7 \mathrm{~g}$ active materials were used, depending on the instrument and cell. Cells with cylindrical geometry were used. Good time resolution allows the kinetics of phase transformations to be studied and Latroche et al. ${ }^{[67 a]}$ showed that the main rate-limiting step of charge-discharge was the kinetics of the $\alpha \Leftrightarrow \beta$ phase transformation. Notably, this was related to the phase interface rather than the diffusion coefficient of hydrogen (or in this case deuterium) at both low and high current rates. This study compared phase evolution (e.g., volume expansion) and fractions with voltage under different electrochemical conditions.

Other in situ NPD studies have shown that the metastable $\gamma$ intermediate phase can form with cobalt-containing alloys (in which $\mathrm{Co}>5 \%$ ) and has intermediate properties between those of the $\alpha$ and $\beta$ phases. ${ }^{[65,67 b, c]}$ An advantage in charging/ discharging via the $\gamma$-phase is that it has been shown to reduce strain (large-scale volume expansion) at the $\alpha-\beta$ interface, which helps to minimize corrosion; a significant problem with alkaline electrolytes. These experiments allow studies of the formation of the $\gamma$-phase, which is only observed in in situ experiments because it is metastable and observed under nonequilibrium conditions. ${ }^{[64,67 c, d]}$ Additionally, cobalt tends to be the most expensive component in the mishmetal, yet gives rise to better performance through the formation of the $\gamma$ 
phase; thus studies have investigated methods to minimize the cobalt content. The substitution of $\mathrm{Ce}$ for $\mathrm{La}$, a Ce/La ratio with minimal Co concentration, or the introduction of Fe with no Co have been shown to undergo similar charge/discharge processes. ${ }^{[67 b]}$ The longer phase life of the $\gamma$ phase and larger phase fraction lead to better cycling performance, even in cobalt-free samples. ${ }^{[67 \mathrm{~d}]}$ This illustrates how manufacturing costs can be improved by undertaking in situ NPD experiments to study the $\gamma$ phase during charging/discharging.

In situ NPD data of these electrodes enabled the determination of 1) the rate-limiting step, which is $\alpha \Leftrightarrow \beta$ phase transformation, during charge-discharge, ${ }_{i}^{[67 a]}$ and 2) the metastable $\gamma$ phase as the reason behind the higher performance of cobaltcontaining alloys. ${ }^{[64,67, d]}$ Here, the NPD study provided unparalleled insight into how these electrodes might be improved, for example, by replacing cobalt with environmentally friendly cations that stabilized the $\gamma$-phase. Researchers have used this information to direct chemical substitution studies.

The cathode tends to be a nickel oxyhydroxide based material and in situ NPD studies have investigated redox processes with both the $\gamma$ - and $\beta$-NiOOH phases directly transforming into $\beta-\mathrm{Ni}(\mathrm{OH})_{2}$ with reduction by a two-phase mechanism. ${ }^{[65,67 \mathrm{e}]}$ These measurements have allowed the elimination of a structural cause behind the second plateau observed in electrochemical reduction; instead, surface properties have been cited as the reason for the second plateau. A recent example also showed that the $C / 5$ and $C / 10$ rates did not influence the charge/discharge kinetics of the structural transformations of $\mathrm{La}_{2} \mathrm{MgNi}_{9} .{ }^{[67 f]}$ These experiments contribute to the understanding of reactivity mechanisms and phase evolution.

A slightly different in situ NPD study can also be used to see the influence of hydrogen or deuterium gas pressure on the composition at constant temperatures to determine optimal loadings and the response of the phases present in the intermetallic-hydride anode, ${ }^{[65,68]}$ for example, pressure-composition isotherms ( $\mathrm{PCl})$. The role of each metallic substitution of $\mathrm{Ni}$ in $\mathrm{LaNi}_{5}$ can be systematically characterized. ${ }^{[66]}$ Combining thermodynamic properties with structural measurements allows in situ data to provide further insight into the behavior of electrodes and batteries because the location of the hydride can be quantified at each step.

In situ NPD studies of NiMH batteries have revealed which phases are essential in stabilizing and optimizing anode performance. Such studies have also shown how substitutions and phase transformations in the cathode influence electrochemistry to reveal, in detail, the link between chemical substitution and the kinetics and thermodynamics of structural transitions. Understanding these links allows researchers to target substitutions that improve battery performance.

\subsection{Lithium-ion batteries}

Early studies on lithium-ion batteries utilized in situ XRD to show structural changes in the cathode and anode materials ${ }^{[56,69]}$ during charging and discharging and a variety of cell designs, X-ray sources, and collection times were experimented with; a recent review highlighted these developments. ${ }^{[54]}$ The most commonly used cell design is a coin cell with holes cut in the stainless-steel casing and spacer. The holes are either replaced with a beryllium window or Kapton tape. The latter has a limited lifetime due to the electrolyte attacking the adhesive and tape itself. A recent exemplifying study illustrates the detail that can be extracted from in situ SXPRD studies. Gummow and co-workers investigated the composition of a lithium-rich transition-metal oxide system that exhibited complex structures, often with persistent intergrowth of two phases, but that could be related to layered $\mathrm{LiCoO}_{2}$ or more generally the $\alpha-\mathrm{NaFeO}_{2}$-type structure. ${ }^{[56]}$ The advantage of these cathodes is that they can deliver a higher capacity when charged to certain voltages. Because the energy density of a lithium-ion battery is limited by the cathode, a high-capacity cathode translates into a higher energy density battery. The evolution of the cathode can be determined from the synthetic method and the range of compositions, phases, and thus evolution can be complex.

This work showed how a composite electrode made of two layered-type materials described above, one lithium-rich and the other lithium-poor, could be cycled and how each phase evolved. The phase composition was determined by using ex situ data of pure powders, and Figure 14 shows the evolution of the lattice parameters of each component during charge/

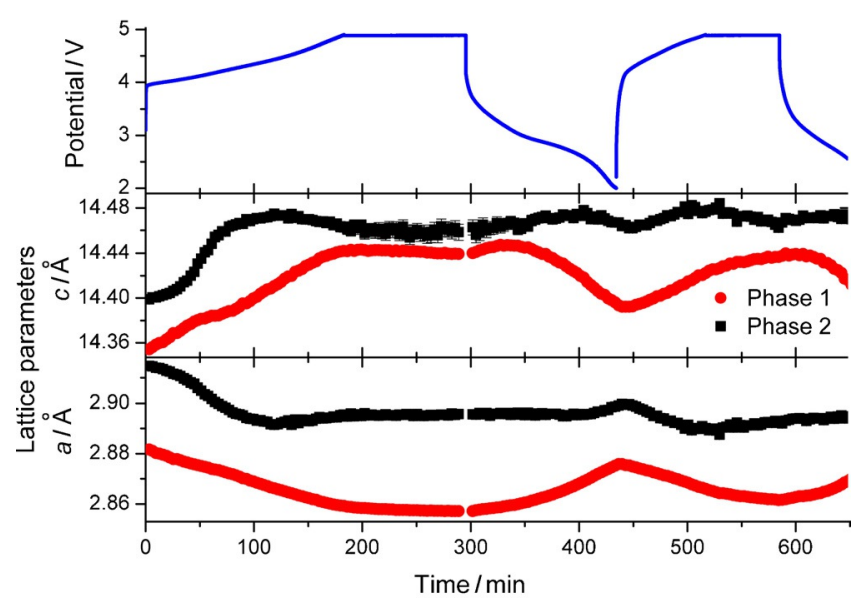

Figure 14. Lattice parameter evolution of a two-phase composite electrode during battery cycling in an in situ XRPD experiment. ${ }^{[56]}$ Reprinted with permission from Ref. [56]. Copyright 2013, The Electrochemical Society.

discharge. ${ }^{[56]}$ Clearly each component is electrochemically active and the rate at which the lattice parameters evolve is different; therefore, each component carries the charge at different rates and/or times during operation. For such an experiment, the similarity of the phases present in the system means that resolution is critical to determine how each phase evolves.

In this case, during charging, the $c$ lattice parameter of both phases increases and the $a$ lattice parameter decreases, with the reverse occurring during discharging. The transition is continuous, which is indicative of a solid-solution reaction. Importantly, the lattice parameters of the electrode do not return to their original value at the end of discharging, which indicates 
that either the electrode is not in its equilibrium state or that structural rearrangements restrict further discharge.

This example shows how in situ SXRPD can reveal the structural evolution of a two-component electrode, identifying both the potential and rate of evolution, and allowing the determination of correlations between phase evolution of the two components, for example, synergistic or sequential evolution. Electrochemically inactive parts of the electrode can also be determined. Such studies can be used to direct the tailoring of the component ratio within composite electrodes. It is important to note that this information is derived for crystalline phases, with in situ PDF methods better suited to the study of amorphous phases.

The key information missing from such in situ XRPD experiments is atomic information on lithium, for example, the occupancy and evolution of the occupancy in each of the phases present in the cathode. NPD, in principle, can provide this information in a time-resolved manner. The first example of the time-resolved tracking of lithium ions in an electrode during battery function was determined for a $\mathrm{Li}_{1+y} \mathrm{Mn}_{2} \mathrm{O}_{4}$ cathode, for which the lithium occupancy was modeled at two crystallographic sites during the charge and discharge processes. ${ }^{[38]}$ This work has been extended to a range of compositions, $x=$ 0 , 0.05, and 0.10, in $\mathrm{Li}_{1+x} \mathrm{Mn}_{2-x} \mathrm{O}_{4}$ by using in situ NPD. ${ }^{[51]} \mathrm{Li}_{1+}$ ${ }_{y} \mathrm{Mn}_{2} \mathrm{O}_{4}$ adopts a cubic spinel structure and Figure 15 shows the evolution of the lithium sites as a function of time and the

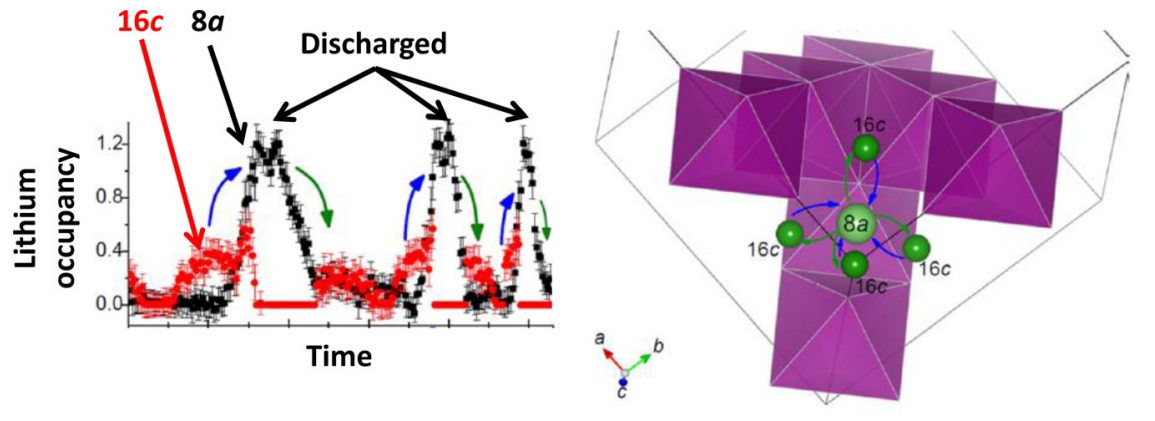

Figure 15. Lithium site-occupancy evolution during charging/discharging of a $\mathrm{Li}_{1+y} \mathrm{Mn}_{2} \mathrm{O}_{4}$ cathode. The region of the structure that is highlighted illustrates the location of the $8 a$ and $16 c$ crystallographic sites. ${ }^{[38]}$ Reprinted and adapted with permission from [38]. Copyright 2013 American Chemical Society.

discharged states are indicated. The mechanism of lithium insertion and extraction was found to differ and this was related to the empirical finding of the differences in the ease of charging relative to discharging batteries containing such electrodes. During lithium insertion, the $16 \mathrm{c}$ site is initially occupied, followed by a depletion of lithium at this site and an increase in the occupancy of the $8 a$ site, whereas during lithium extraction the majority of the process occurs from the $8 a$ site, and only in the later stages are both sites occupied (Figure 15). Notably, the lithium site evolution and occupancy fluctuation are also manifested in the lattice parameters, with changes in the lithium parameters influencing the rate of change (e.g., expansion or contraction) of the lattice. Therefore, lattice evolution could be correlated to the population and depopulation of the lithium sites as a function of time and battery potential. This level of structural detail with respect to the electrochemical state of the battery is unprecedented in the literature.

The related in situ NPD study of $\mathrm{Li}_{1+x} \mathrm{Mn}_{2-x} \mathrm{O}_{4}$ compositions shows how phase evolution varies with the Li content $(x)$ in the original cathode. ${ }^{[51]}$ The cathode exhibits only solid-solution behavior at one extreme $(x=0.10)$, whereas it shows a sequence of two two-phase reactions at the other $(x=0)$. These phase transitions and structural evolution correlate to the slope and features in the electrochemical charge-discharge curves. These cells were cycled at the $C / 20$ rate and features in the $\mathrm{d} Q / \mathrm{d} V$ plots correlated to both the phase evolution and lithium site-occupancy factors. Notably, the nonuniform rate of lithium extraction is supported by the appearance of time and potential domains with fast and slow lithium extraction. Overall, the initial composition has a significant influence on phase evolution and determines the cathode performance.

The time-resolved tracking of lithium occupancy and distribution was extended to the $\mathrm{LiMn}_{1.5} \mathrm{Ni}_{0.5} \mathrm{O}_{4}$ cathode ${ }^{[42]}$ and $\mathrm{Li}_{4} \mathrm{Ti}_{5} \mathrm{O}_{12}$ anode ${ }^{[41]}$ by using custom-designed pouch batteries and $\mathrm{Li}_{1+x} \mathrm{Mn}_{2-x} \mathrm{O}_{4}$ by using $\mathrm{Ti}-\mathrm{Zn}$ alloy coin-type half-cells. ${ }^{[51]}$ These battery designs allow researchers to make batteries in laboratories with limited amounts of starting materials (e.g., gram scale) with the capability of tracking lithium evolution during battery function. Interestingly, the battery performance at the current rates investigated resembles that of either smaller coin or commercial cells. This is expected for work examining the $\mathrm{Li}_{1+y} \mathrm{Mn}_{2} \mathrm{O}_{4}$ cathode ${ }^{[38]}$ because this uses what is effectively a commercial cell.

Another aspect of in situ NPD is that the entire battery can be in the neutron beam, which allows the whole electrode to be probed. Using a roll-over cylindrical cell, researchers were able to show how the reaction mechanisms evolved in a $\mathrm{LiFePO}_{4}$ cathode. They showed the first experimental evidence for the presence of simultaneous reaction mechanisms occurring in this electrode during battery function. ${ }^{[28]}$ Structural characteristics of both the solid-solution-type and two-phase-type reaction mechanism were observed during certain states of charge, as shown in Figure 16. The changing lattice parameter is indicative of a solid-solution reaction, whereas the changing phase fraction of $\mathrm{LiFePO}_{4}$ and $\mathrm{FePO}_{4}$ is indicative of the twophase reaction. Figure 16 also highlights the parameters that can be extracted from in situ NPD experiments: the electrochemical parameters of potential and current, and also the structural parameters of lattice and phase fractions in this case. The cases presented above for $\mathrm{Li}_{1+y} \mathrm{Mn}_{2} \mathrm{O}_{4}, \mathrm{LiMn}_{1.5} \mathrm{Ni}_{0.5} \mathrm{O}_{4}$, and $\mathrm{Li}_{4} \mathrm{Ti}_{5} \mathrm{O}_{12}$ also show the atomic structural parameters, especially for lithium, in addition to that shown in Figure 16. 


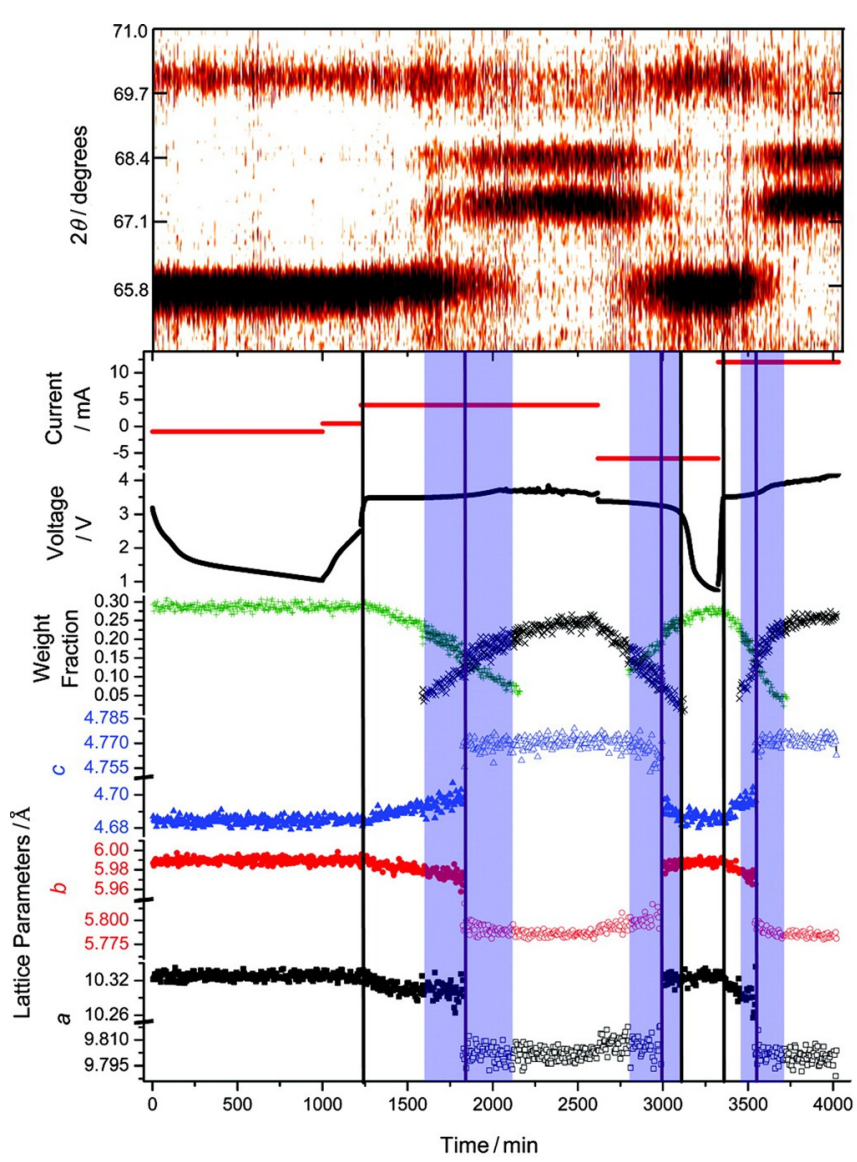

Figure 16. A selected region of in situ NPD data (top) from a roll-over cell with the $\mathrm{LiFePO}_{4}$ cathode; the applied current (red line) and cell potential (black line), weight fraction of $\mathrm{LiFePO}_{4}$ (green crosses) and $\mathrm{FePO}_{4}$ (black crosses), and lattice parameters of $\mathrm{LiFePO}_{4}$ (closed symbols) and $\mathrm{FePO}_{4}$ (open symbols) are also shown (bottom). Shaded vertical regions are locations where simultaneous solid-solution and two-phase reactions are observed. ${ }^{[28]}$ Reprinted with permission from [28]. Copyright 2012 American Chemical Society.

Therefore, the bulk phase evolution of the cathode during charging-discharging, similar to the $\mathrm{Li}_{1+x} \mathrm{Mn}_{2-x} \mathrm{O}_{4}{ }^{[51]}$ cathode studies and the in situ XRPD studies, can be determined from in situ NPD. However, in situ NPD flourishes in the ability to track lithium in real time during charging/discharging of whole batteries. The lithium site-occupancy factors and phase evolution can be related to features in the electrochemical curves, including for commercial cells and cells optimized specifically for NPD; this allows exploration of the parameter space and directs researchers towards improved electrode materials.

\subsection{Sodium-based batteries}

Molten-salt-based sodium batteries functioning at relatively high temperatures have been investigated and commercialized. ${ }^{[70]}$ They require molten sodium salts and typically run at temperatures above $200^{\circ} \mathrm{C}$; however, some newly developed salts have brought the operational temperatures down to $90^{\circ} \mathrm{C}$. Typical components within these cells are $\mathrm{Na} / \mathrm{NaCl}, \mathrm{Ni} /$ $\mathrm{NiCl}_{2}$, or $\mathrm{Fe} / \mathrm{FeCl}_{2}$ electrodes with $\beta$-alumina as the electrolyte scaffold and $\mathrm{NaAlCl}_{4}$ as a secondary electrolyte. ${ }^{[70 a]}$ There is a reaction front that propagates in these batteries through the $\beta$ alumina electrolyte consuming $\mathrm{NaCl}$ to form $\mathrm{FeCl}_{2}$ or $\mathrm{NiCl}_{2}$ and $\mathrm{Na}^{+}$(or Na metal) during charging and the reverse during discharging. Very little diffraction work on these batteries as a whole has been conducted; three reports have been identified to date. ${ }^{[70 a, 71]}$ Neutron work is particularly elegant because the large cell shown in Figure $17 \mathrm{a}$ is used with two different batteries at two states of charge (discharged and half charged). Researchers were able to use radiographic images to illustrate physical changes in the distribution of species inside the batteries (Figure 17c and $d$ ) and to realize a 3D tomographic image of the battery (Figure $17 \mathrm{~b}$ ). The internal structure of the battery could be determined and the differences between the states of charge illustrated, that is, the reaction front and sodium level in the anode (Figure $17 \mathrm{c}$ and $\mathrm{d}$ ). In addition, because neutron scattering is nondestructive, the same batteries were measured on a residual stress diffractometer by taking measurements at various gauge volumes inside the battery (Figure 17e). Clearly, as shown in Figure $17 \mathrm{f}$, the crystalline phase composition inside the battery evolves from the outside towards the battery center, which is related to both the internal structure and the reaction front progressing through the battery. Phase compositions and ratios can be quantified and tracked throughout the battery, and differences in the phase composition between the discharged and half-charged battery compared. In this case, the half-charged battery contained a significant proportion of $\mathrm{Na}_{6} \mathrm{FeCl}_{8}{ }^{\left[{ }^{[0 a]}\right.}$ Therefore, by coupling tomography and diffraction, researchers visualized the reaction front and phase composition of these batteries, all without opening the batteries. Thus, these relatively large batteries can be probed by using neutron diffraction methods.

An in situ energy-dispersive XRPD study described the phase evolution and kinetic parameters. ${ }^{[71 a]}$ High-energy X-rays were used to penetrate into the full-sized metal halide battery (Figure 18a). For such energy-dispersive XRPD experiments, a "white beam" or beam with a distribution of X-ray wavelengths was used and the detector measured the intensity versus energy of the scattered beam. Data such as that shown in Figure $18 \mathrm{~b}$ is produced, for which the $x$ axis is energy and the $y$ axis is the pattern number; in this case, corresponding to the depth inside the cell. The $y$ axis can be altered to a fixed position inside the cell and phase evolution at this position (defined as a gauge volume) can be examined as a function of discharge (Figure 18c). Using peak identification and fitting regimes, these researchers were able to show the reaction processes that occurred to validate the existence of the $\mathrm{Na}_{6} \mathrm{FeCl}_{8}$ phase. They also showed when phase evolution occurred with respect to the battery state of charge (a temporal study) and then at a fixed state of charge where the reaction front was located (a spatial study). Therefore, excellent space and time information can be extracted from these batteries by using such an experiment. The next step would be to capture this information for the entire battery height, similar to that shown above with neutrons.

In situ NPD as a depth-sensitive probe has revealed the phase evolution of a molten salt battery and reaction progres- 
a)

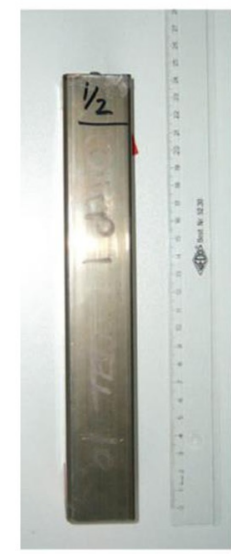

b)

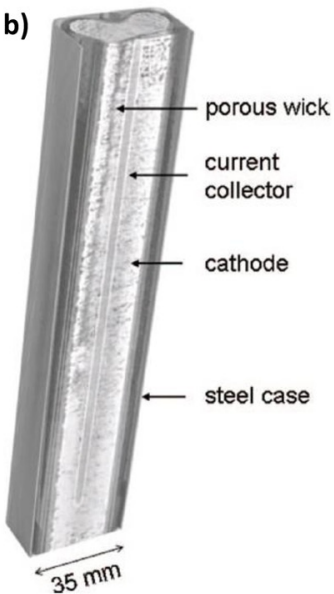

c)

$95 \mathrm{~mm}$

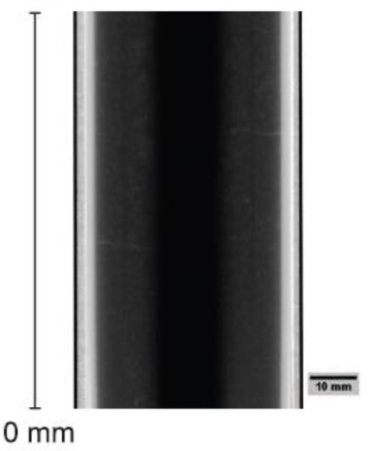

d)

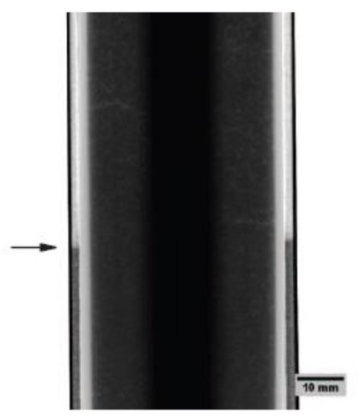

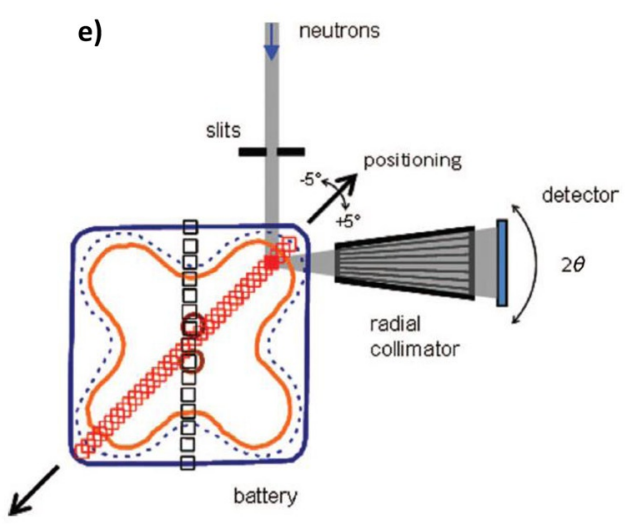

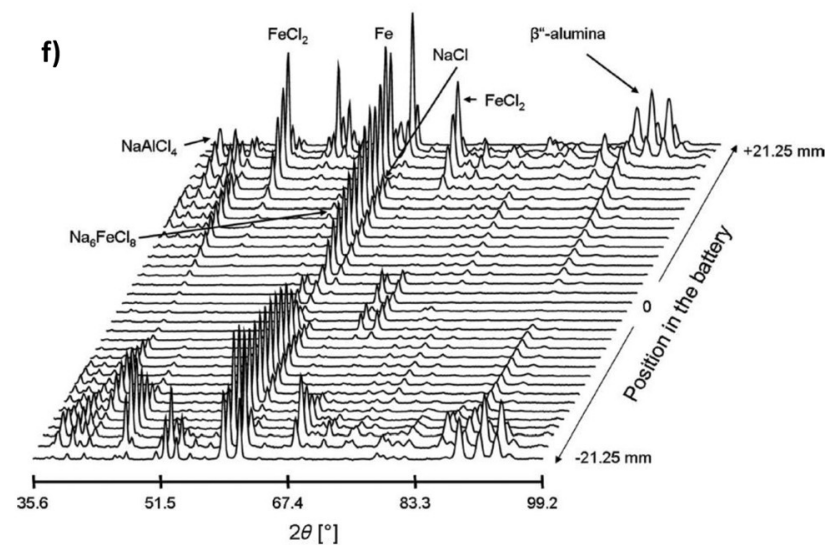

Figure 17. a) An image of the molten-salt sodium battery, b) the internal schematic, c) and d) tomographic images of the battery, e) the gauge volumes for NPD studies, and f) the resulting NPD patterns. ${ }^{[70 a]}$

sion in these devices. Phase evolution as a function of discharge was also determined by using energy-dispersive XRPD. From this information, researchers can determine which phases are present or formed, and whether these are soluble, electrochemically active, or adverse to performance. This assists in the modeling of battery degradation and performance. However, as evident from the results in Figures 17 and 18, there is significantly more complexity to in situ NPD or XRPD experiments of molten-salt batteries, relative to the same experiments on lithium-ion batteries discussed in Section 6.3. Notably, although only a portion of battery evolution is captured (the gauge volume), this is sufficient to determine valuable information concerning battery function.

The question remains whether the gap between a lithiumion battery and a sodium molten-salt battery can be bridged. This has led to dramatic developments and advances in sodium-ion batteries, which work in a similar manner to lithium-ion batteries, but use sodium as the energy carrier. The research drive here is the cost of sodium, which is significantly cheaper than lithium due to the abundance of sodium in the Earth's crust, in addition to the ability to use aluminum current collectors for both electrodes in a sodium-ion battery. ${ }^{[8]}$ The latter is fairly significant because $\mathrm{Cu}$ current collectors are required at the negative electrode in lithium-ion batteries to prevent $\mathrm{Li}-\mathrm{Al}$ alloy formation and $\mathrm{Cu}$ is becoming more expen- sive. ${ }^{[8]}$ Aluminum current collectors also reduce the weight of the battery and, for in situ diffraction experiments, reduce the number of components in the beam. Other advantages in sodium-ion systems are similar reduction potentials $(2.94 \mathrm{~V}$ versus $\mathrm{H}_{2} / \mathrm{Pt}$ relative to $3.04 \mathrm{~V}$ vs $\mathrm{H}_{2} / \mathrm{Pt}$ for Li) and the similarity in chemical properties. ${ }^{[8,72]}$ The disadvantages include the size of the sodium cation, which requires larger volumes for insertion/extraction, and the relatively sluggish insertion/extraction reactions relative to lithium predominantly due to kinetic effects. ${ }^{[8,72]}$ Nonetheless, sodium-ion batteries are now attracting significant interest, as demonstrated by approximately 400 publications until 2012, 98 in 2012, and around 220 in 2013 (Web of Science).

Diffraction has played a key role in the development of components for sodium-ion batteries and work has also determined the time-resolved sodium and lattice evolution of electrodes during charging and discharging. This insight is very powerful in sodium-ion battery electrodes because the major issues with positive electrodes are the amount of sodium that can be reversibly inserted/extracted and the number of major structural distortions that occur during the insertion/extraction process. Specifically, some cathodes under study include $\mathrm{Na}_{x} \mathrm{CoO}_{2}{ }^{[73]} \quad \mathrm{Na}_{x} \mathrm{MnO}_{2}{ }^{[74]} \mathrm{Na}_{x} \mathrm{CrO}_{2}{ }^{[75]} \mathrm{Na}_{x} \mathrm{FePO}_{4}{ }^{[76]} \mathrm{Na}_{x} \mathrm{M}_{2}\left(\mathrm{XO}_{4}\right)_{3}$, and various compositions in the $\mathrm{Na}_{x} \mathrm{M}_{2} \mathrm{O}_{2 y}\left(\mathrm{PO}_{4}\right)_{2} \mathrm{~F}_{3-y}$ series, in which $\mathrm{M}=\mathrm{V}, \mathrm{Fe}, \mathrm{Co}, \mathrm{Mn}$, and $\mathrm{Ni}$ and $\mathrm{X}=\mathrm{Si}, \mathrm{P}, \mathrm{S}$, and $\mathrm{Mo}{ }^{[8,77]} \mathrm{To}$ 
a)
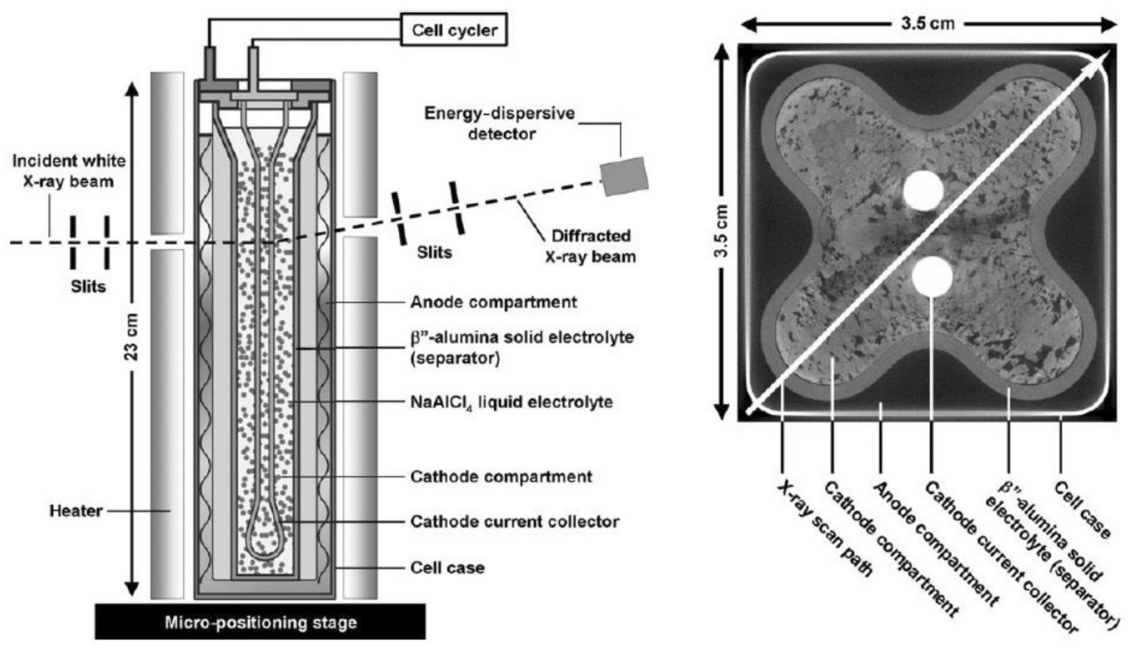

b)

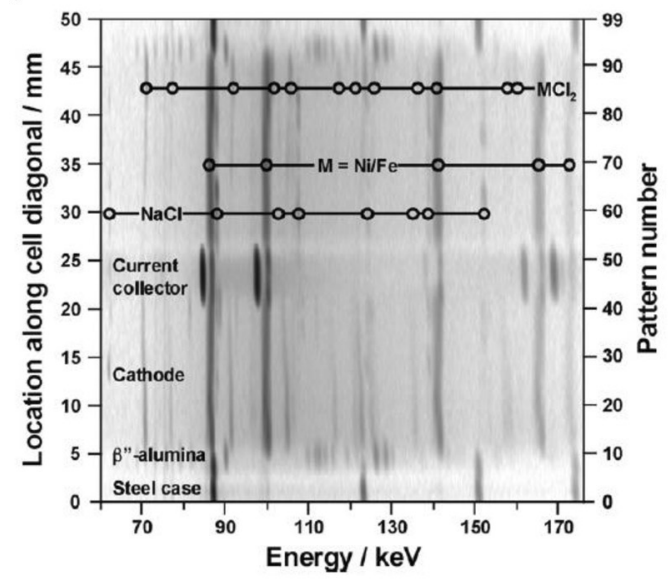

c)

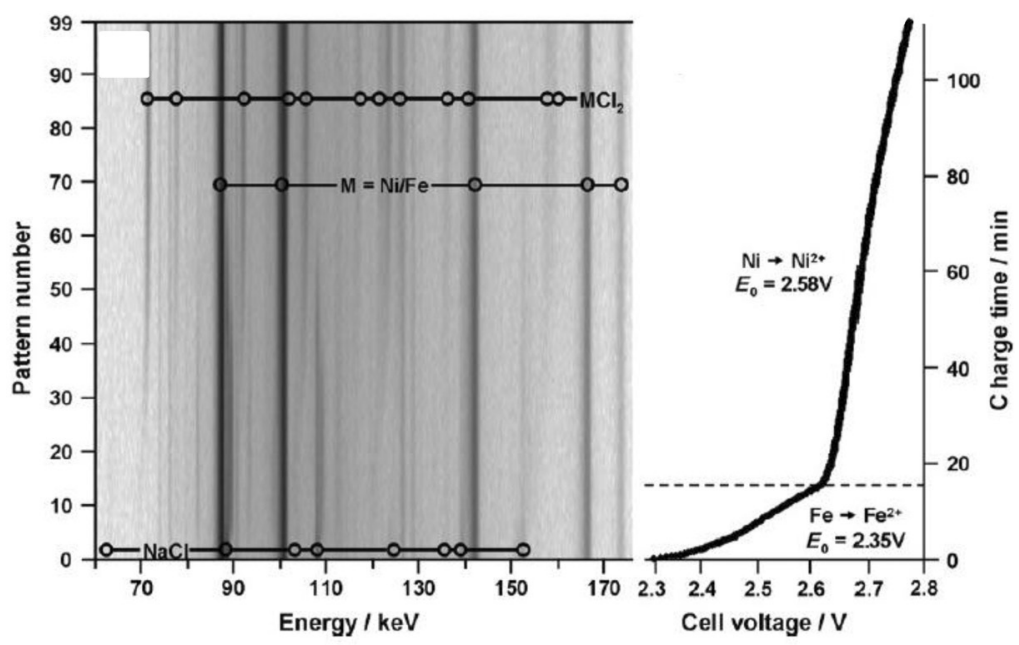

Figure 18. a) Schematic illustration of the sample stage and experimental setup and the computed tomographic image of the cell. Contour-type plots of the diffraction patterns b) along the cell diagonal at a fixed state of charge and c) at a fixed position during discharge with the potential profile shown. ${ }^{\text {[7ia] }}$

date, a number of in situ XRD experiments have been carried out, but these have focused on insertion/extraction reactions under equilibrium or low-current conditions ${ }^{[73,74,76,78]}$ and typically avoid time-resolved influences. The cells used are often based on coin cells with either electrodes spread on the current collector or as pellets. Depending on whether synchrotron or laboratory X-ray radiation is used, precludes whether transmission or reflection geometry is preferred. The radiation source also determines the collection times, and hence, the applied charge/discharge (current) rates used.

A recent series of studies of the $\mathrm{Na}_{x} \mathrm{~V}_{2} \mathrm{O}_{2 y}\left(\mathrm{PO}_{4}\right)_{2} \mathrm{~F}_{3-y}$ system by using SXRPD highlight how sodium atomic parameters can be tracked in a time-resolved manner. ${ }^{[79]}$ Researchers investigated two compositions with an overall vanadium oxidation state of about $3.8^{+}$and $4^{+}$, and found that the reaction mechanism evolution was distinctly different in each of these, even though the same redox couple $\left(\mathrm{V}^{4+}\right.$ to $\left.\mathrm{V}^{5+}\right)$ was involved in the charge/discharge or sodium extraction/insertion processes. Figure 19 shows the subtle differences in reaction mechanism evolution during charging with an additional phase present in the $\mathrm{V}^{4+}$ system, as identified by the additional reflection(s) in the collated in situ data. Using these data, researchers were able to model the sodium site occupancies at two sodium sites in the $P 4_{2} / \mathrm{mmm}$ structural model during the solid-solution reaction mechanism regimes. The role each site played and their interplay, depending on the electrochemical conditions (e.g., during a potentiostatic step), and battery history illustrated how the electrode functioned at an atomic level. Figure 20 shows the sodium site evolution as a function of charge and discharge in the $\mathrm{Na}_{x} \mathrm{~V}_{2} \mathrm{O}_{2 y}\left(\mathrm{PO}_{4}\right)_{2} \mathrm{~F}_{3-y}(y=0.8)$ electrode. The Na2 site appears to be "active" and decreases in $\mathrm{Na}$ content after the first two-phase region, whereas the Na1 site remains virtually unchanged in this period. Additionally, during the latter parts of discharge prior to the two-phase region the same behavior is noted with the $\mathrm{Na} 2$ site being the most "active" in sodium content changes. Therefore, sodium evolution can be clearly related to the electrochemical curves.

This in situ experiment of the $\mathrm{Na}_{x} \mathrm{~V}_{2} \mathrm{O}_{2 y}\left(\mathrm{PO}_{4}\right)_{2} \mathrm{~F}_{3-y} \quad(y=0.8)$ electrode highlights the need for time-resolved in situ experimentation because all ex situ evidence prior to this experiment suggested a wholly solid-solution mechanism for the charge/ discharge behavior of this electrode. ${ }^{[80]}$ A relatively straightfor- 

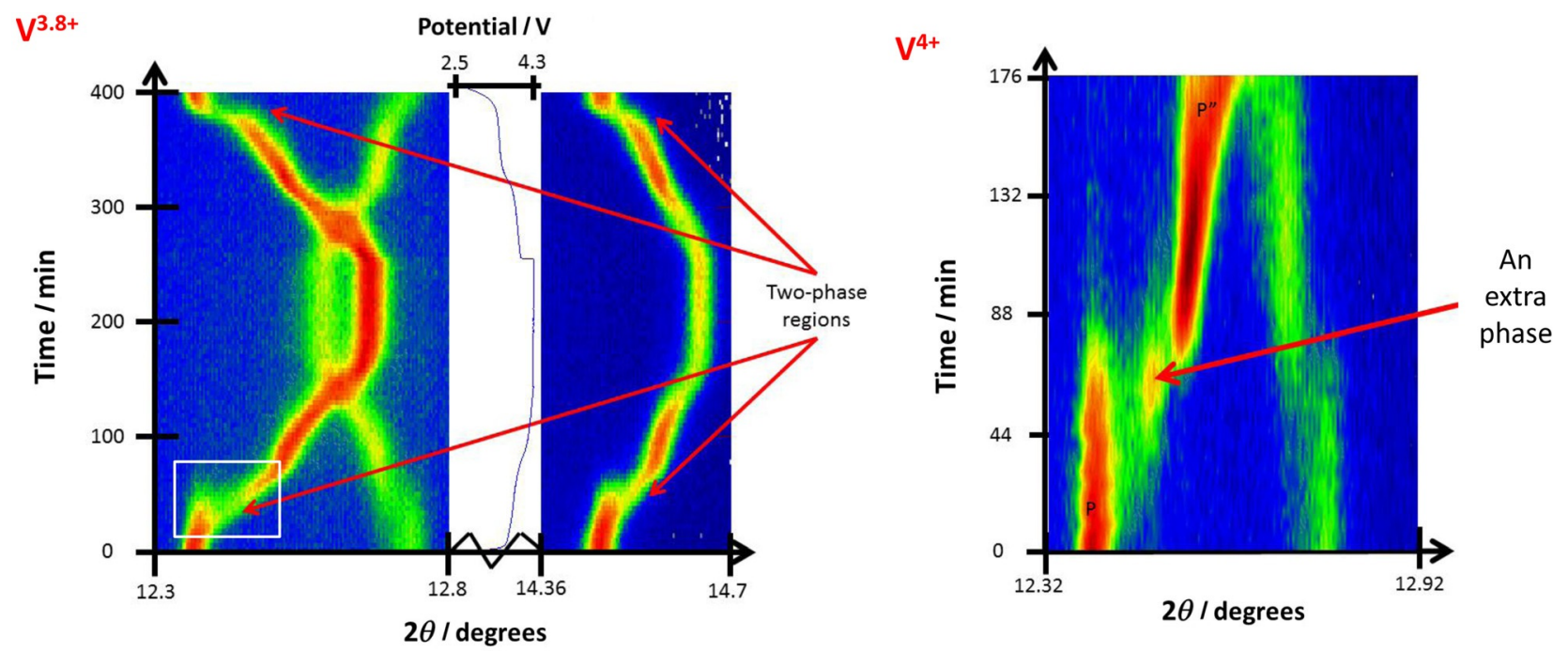

Figure 19. Contour plots of SXPRD data of the $\mathrm{V}^{\approx 3.8+}$ and $\mathrm{V}^{4+}$ electrodes in the $\mathrm{Na}_{x} \mathrm{~V}_{2} \mathrm{O}_{2 y}\left(\mathrm{PO}_{4}\right)_{2} \mathrm{~F}_{3-y}$ family with the two-phase regions highlighted during the charge/discharge processes in the $\mathrm{V}^{\approx 3.8+}$ sample and the potential profile. The presence of an additional phase in the $\mathrm{V}^{4+}$ electrode during the two-phase reaction is indicated. ${ }^{[79]}$ Reprinted with permission from Ref. [79]. Copyright 2014 American Chemical Society and reproduced with permission from The Royal Society of Chemistry.

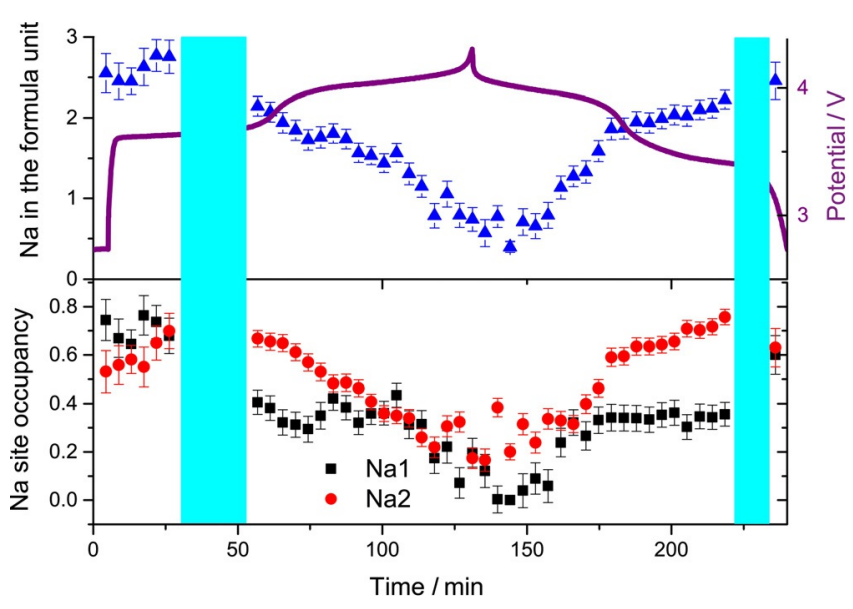

Figure 20. The evolution of the Na site occupancy at two Na sites (red and black) and the total $\mathrm{Na}$ content (blue) in the $\mathrm{Na}_{x} \mathrm{~V}_{2} \mathrm{O}_{2 y}\left(\mathrm{PO}_{4}\right)_{2} \mathrm{~F}_{3-y}$ model, as determined by Rietveld analysis of the structural model by using in situ SXRPD data. Shaded regions are two-phase reactions and the potential profile is also shown. ${ }^{[79 a]}$ Reproduced with permission from The Royal Society of Chemistry.

ward coin-cell experiment at a synchrotron source and a relatively fast charge/discharge rate illustrated that the reaction evolution was more complicated than a simple solid-solution mechanism, but also that the phases present were distorted structurally, adopting the same structural motif (e.g., space group). Additionally, the ex situ SXRPD data collected for the electrode after extraction from the coin cell indicated a higher than expected $\mathrm{Na}$ content of $2.26(6),{ }^{[80]}$ whereas in situ data at the same point in charge indicted a Na content of $1.15(13)^{[79 a]}$ at the first cycle. Notably, the expected Na content based on the amount of charge transferred through the electrode (electrochemistry) was closer to the in situ results, which suggested some equilibration processes occurred during the extraction of the electrode for the ex situ studies; this further highlights the importance of in situ experiments.

The importance of detailed structural definition in in situ battery experimentation was demonstrated by using SXRPD to investigate the $\mathrm{Fe}\left[\mathrm{Fe}(\mathrm{CN})_{6}\right]_{1-x} \cdot y \mathrm{H}_{2} \mathrm{O}$ and $\mathrm{Fe}\left[\mathrm{Co}(\mathrm{CN})_{6}\right]$ electrode materials. Researchers found that two models were appropriate to describe the collected data; these were subtly different with one accounting for the presence of vacancies, often found in these structures, ${ }^{[81]}$ whereas the other did not. Figure 21 shows how the lattice parameters, and hence,

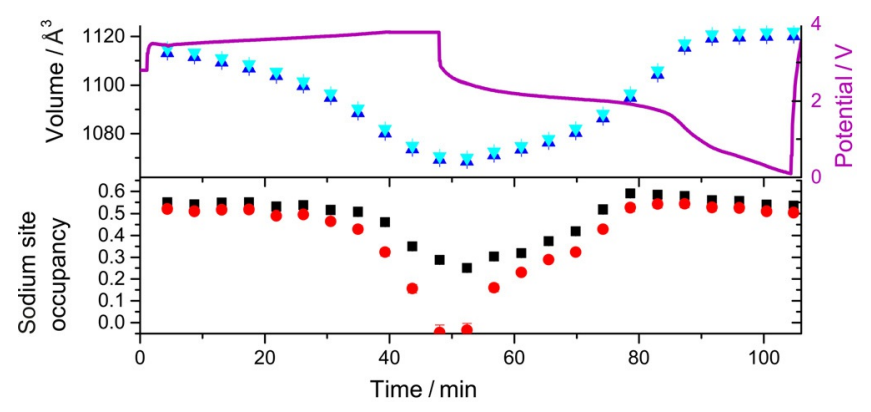

Figure 21. The Na site occupancy and lattice evolution of a Fe[-

$\left.\mathrm{Fe}(\mathrm{CN})_{6}\right]_{1-x} \cdot y \mathrm{H}_{2} \mathrm{O}$ electrode during electrochemical cell function. Two models are used to describe the structure, one containing vacancies and the other free of vacancies; the volume in both models follows the same trend (blue symbols), but the Na site occupancies are different, especially in the charged (Na extracted) state (red and black symbols). ${ }^{[82]}$ Reproduced with permission from The Royal Society of Chemistry.

volume, follow the same process during the in situ electrochemical steps, whereas subtle differences are noted in the sodium content of the electrode. ${ }^{[82]}$ This demonstrates that subtle differences in the structural model can distort the obtained atomic parameters and that models must be appropriately selected and refined with chemical and physical plausibil- 
ity in mind. Interestingly, this study also showed that this electrode appeared to take up sodium from the electrolyte during cell construction and storage, transforming the sodium-free electrode, an anode, to a sodium-containing cathode ready for battery operation.

Therefore, in situ studies of electrodes in ambient-temperature sodium-ion batteries are advancing this relatively young research field. The number of X-ray instruments available relative to neutron-based instruments means that there is likely to be an ever-increasing number of in situ diffraction-based studies. The need for these in situ diffraction studies is compounded by the fact that the structural changes associated with sodium insertion/extraction during charge/discharge are significantly larger and often more adverse than the respective insertion/extraction reactions with lithium.

\subsection{Future batteries}

The next generation of lithium-ion batteries with high capacity are essential for future technology and the electric vehicle market. However, other alternatives have been found, including lithium-air technology, lithium-sulfur batteries, and the sodium-ion batteries discussed in Section 6.4.

Lithium-air technology has been exploited for batteries by reacting lithium with oxygen directly from the air. The reaction is $2 \mathrm{Li}+\mathrm{O}_{2} \rightleftarrows \mathrm{Li}_{2} \mathrm{O}_{2}$ and can achieve a very high capacity of $1200 \mathrm{~mA} \mathrm{hg}^{-1}$, which is significantly higher than that of conventional insertion cathodes. Although the lithium-air system can offer high energy density, the power density is relatively low. To address this problem, cathode materials with large surface areas are key to lithium-air systems because the reactions occur at the surfaces of the cathode during the charging/discharging process. ${ }^{[83]}$ However, the practical development of a lithium-air battery is prevented by difficulties in mastering lithium metal and oxygen electrodes in an efficient, rechargeable, and safe battery configuration. ${ }^{[84]}$

Another promising candidate for a high-energy system is the lithium-sulfur battery. Sulfur as an electrode host has the highest theoretical capacity of $1672 \mathrm{mAhg}^{-1}$, which is more than 10 times that of the commercially used transition-metal oxides and phosphates. ${ }^{[85]}$ The lithium-sulfur battery is based on the electrochemical redox reaction: $16 \mathrm{Li}+\mathrm{S}_{8} \rightleftarrows 8 \mathrm{Li}_{2} \mathrm{~S}$. Although sulfur cathode materials feature advantages such as low cost, long cycle-life, and an intrinsic protection mechanism from overcharging ${ }_{1}^{[86]}$ the poor electrical conductivity and high solubility of polysulfides $\left(\mathrm{Li}_{2} \mathrm{~S}_{x}\right)$ formed during charging/discharging in liquid organic electrolytes limit its utilization as a cathode material. Several strategies are used to solve these problems, including embedding sulfur into a conductive matrix to increase the electrical conductivity and using polymer or ionic-liquid-based electrolytes to address the solubility issue. ${ }^{[87]}$ The evolution of these batteries has been pushed to meet the demands of the automotive industry; however, so far, only modest changes, involving one or at most two battery components, have been commercially proposed, always maintaining an overall chemistry based on insertion processes.
Enabling technologies beyond lithium-ion and other commonly used batteries will lead to a significant cost reduction and an increase in the electrochemical performance, resulting in an expansion in applications. Below we provide some examples of preliminary work undertaken with in situ and diffraction-based experiments on future battery systems.

Lithium-air or lithium-oxygen batteries, as described above, are one of the most extensively studied metal-air systems. Major questions remain, such as what species are deposited on the air electrode and are the oxidized (discharge) products soluble/insoluble in different solvents, how can the metallic electrode (Li) be protected from air and oxidation on the electrode surface, how can the electrochemical performance be improved, how is the best combination of electrolytes chosen, and how can the oxygen reduction reaction be investigated? In situ NPD may play a leading role in the development of these battery systems, by following and identifying the longrange ordered phases during discharging/charging.

Before describing a design for an electrochemical cell for in situ NPD studies, first surface area is considered, noting that the desired products are often formed on the surface of the electrodes. A simple experiment was designed by using conventional vanadium cans (such as those used in NPD studies) filled with deuterated electrolytes, a magnesium electrode, and an air electrode (metal-air battery; see Figure 22). The inten-

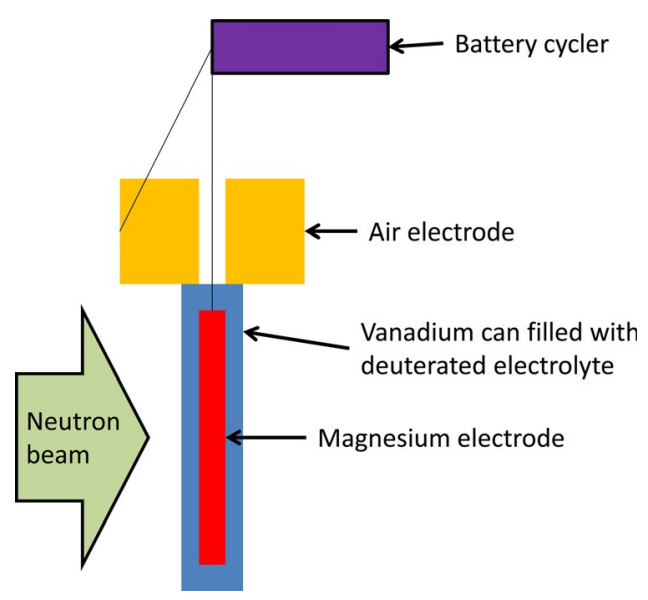

Figure 22. A simple design of a magnesium-air battery for use in an NPD experiment.

tion was to study the salts produced during the electrochemical reaction at the surface of magnesium during discharging. The use of a magnesium rod produced virtually no signal in diffraction data from the salts; only magnesium was observed. The use of a magnesium ribbon electrode increases the surface area upon which the salts can form, and hence, the amount of salt formed, resulting in the detection of the salt, albeit in small quantities, as shown in Figure 23. $\mathrm{A} \mathrm{MgCl}_{2}$ and $\mathrm{D}_{2} \mathrm{O}$ electrolyte is used and the phases identified in Figure 23 are $\mathrm{Mg}(\mathrm{OD})_{2}$ and $\mathrm{Mg}$. The preferred orientation here is significant and has to be accounted for in the model. Therefore, a significant quantity of the products in these metal-air type batteries needs to form to detect them by using NPD. 


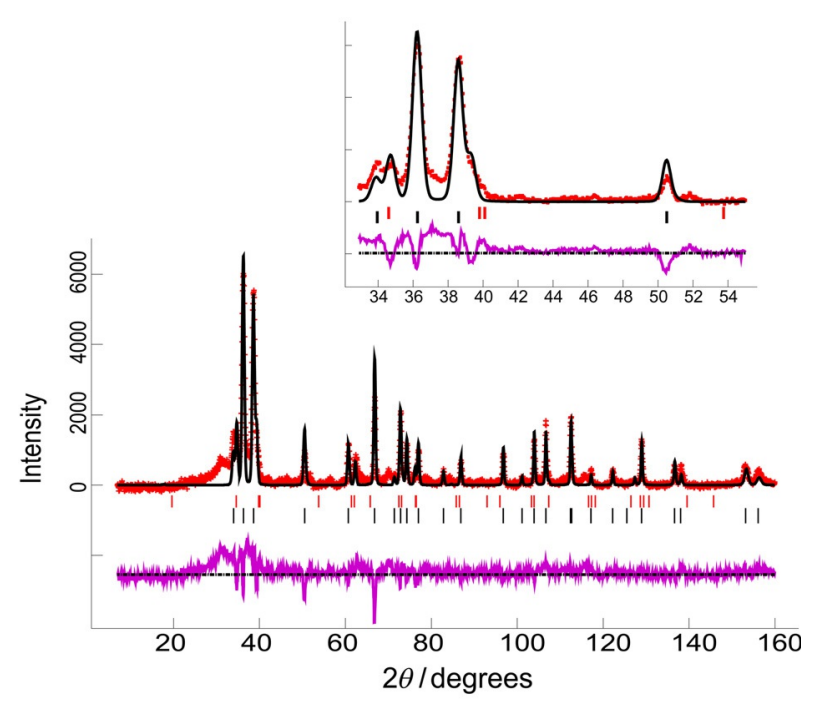

Figure 23. Preliminary Rietveld refined fit of the $\mathrm{Mg}(\mathrm{OD})_{2}$ and $\mathrm{Mg}$ structural models to NPD data of the cell shown in Figure 22 after discharge. tion of X-rays with matter. Here smaller coin cells or electrolyte-rich cells can be designed and implemented. To the best of our knowledge, only one in situ XRPD study has probed lithium-air batteries, ${ }^{[88]}$ in which the researchers investigated the evolution of the $\beta-\mathrm{MnO}_{2} / \mathrm{Pd}$ air electrode during battery operation by using a commercially available in situ XRPD cell. They illustrated the formation of $\mathrm{Li}_{2} \mathrm{O}_{2}$ and $\mathrm{Li}_{2} \mathrm{O}$ based on a limited number of very weak reflections in both ex situ and in situ data. ${ }^{[88]}$ The analysis was qualitative and other factors (changes in $\beta-\mathrm{MnO}_{2}$, for example) were not conclusively ruled out. Further work is required to verify phase evolution at the air electrode. Work has also begun to explore the evolution of solid electrolytes, such as $\mathrm{Li}_{6} \mathrm{PS}_{5} \mathrm{Br}^{\left[{ }^{[99]}\right.}$ by using in situ XRPD during lithium-air battery operation to verify their inactivity (or structural robustness) during cycling. In such cases, no structural changes are a great result. In lithium-air or lithium-oxygen battery studies with in situ XRPD the key concern becomes the ability to detect and reasonably analyze lithium and lithiumcontaining compounds, especially if decomposition or reversible products formed are not crystalline.

Another type of battery in the research and development phase is the all-solid-state battery, in which the typically used electrolyte solution is replaced by a solid electrolyte that features high ionic conductivity. Although more complicated in construction, due to the need to mix the cathode with the solid electrolyte and the need to consider interface effects, the safety, temperature, and leakage issues found in conventional liquidcontaining batteries are essentially overcome. These batteries are fairly ideal for in situ NPD studies. This is because they fea-

Figure 24. Lithium-air cell designs for in situ NPD studies. The top view of one cell is shown along with the side view of the concentric design.

Working with this knowledge, a lithium-air electrochemical cell for NPD studies was designed (Figure 24). The first iteration of the cell essentially consisted of lithium metal, a glass-fiberbased separator containing electrolyte, and an air electrode on nickel mesh all wrapped around a hollow aluminum cylinder. Appropriate hose clamps were used on the outside of the mesh to secure the construction and to provide an electrical contact. The lithium metal is sealed with wax or epoxy at the base and top of the construction to avoid direct air $/ \mathrm{O}_{2}$ contact with the metal. This is similar to the construction shown in Figure 24; however, to increase surface area for reactions to take place and to observe the products, the second iteration of the design featured multiple concentric cells, each with slightly larger diameter. Each cell is connected in series (Figure 24). The iterative improvement of cell design is critical to the progress of such experiments towards success and generally multiple experiments are required in this process.

The advantage in situ XRPD has for examining lithium-air batteries is the generally larger flux and greater overall interac- ture no electrolytes that need to be deuterated and no liquid components to give unwanted background/signal contributions in the collected patterns. Moreover, the components of the battery tend to be crystalline or glass ceramics. A simple all-solid-state battery design is shown in Figure 25, in which a clamp is used to apply pressure to pellets of the anode, solid electrolyte, and mixture of solid electrolyte and cathode. Kapton tape is used to seal the cell from air prior to removal from the glove box. The neutron beam is adjusted to only expose the cell components, as shown in Figure 25. The simple design shown in Figure 25 may provide sufficient detail on the components of interest, but the issue with these batteries is the charge/discharge time. This is because solid-state batteries constructed in this manner require relatively slow charge/discharge rates to avoid polarization and to ensure that the entire pellet is utilized. Therefore, this requires a significant amount of diffractometer time to conduct a single in situ experiment. A compromise needs to be reached between charge/discharge rates, the thickness of the pellets used, and the quality of the 


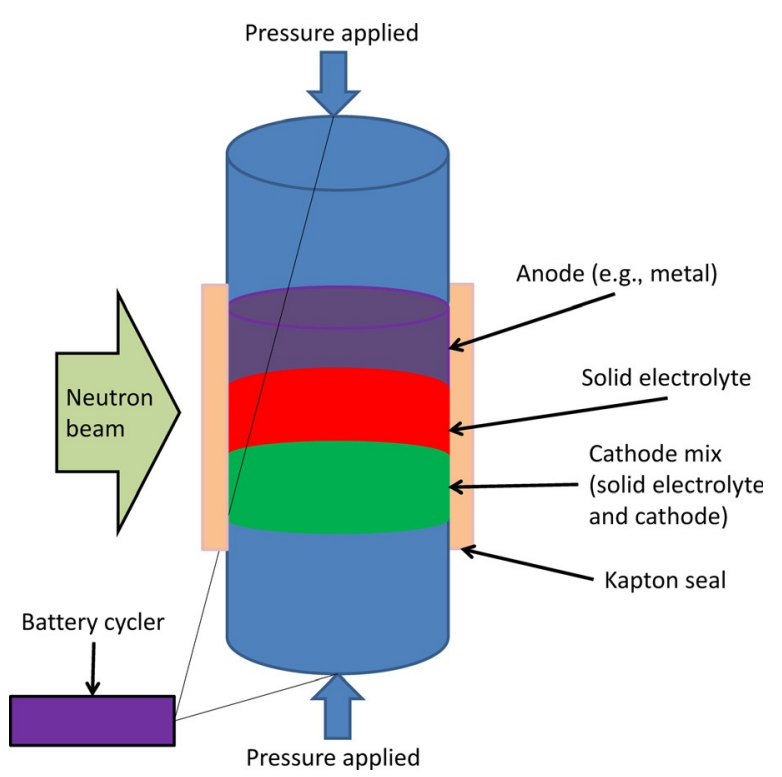

Figure 25. A schematic illustration of a simple all-solid-state battery that can be used for in situ NPD experiments.

diffraction data. This issue may be addressed by using thin-film or thin-pellet solid-state batteries potentially with XRPD. Here, the electrode or electrolyte can be probed and the charge/discharge rates can be dramatically improved. The long path lengths and sample geometry mean that careful calculations of the beam attenuation through the cell need to be undertaken. Further care needs to be taken to consider the preferred orientation of certain components, for example, if the cathode is aligned in a particular direction from the film growth procedure.

The advantage gained by using XRPD with solid-state batteries is not as significant as that of NPD. The key point here is that the liquid electrolyte is transparent to X-rays and troublesome with neutrons. Solid-state batteries may complicate X-ray studies because significant attenuation and orientation effects become more important. Thus, there is a need to choose an appropriate type of cell and radiation for the scientific question being asked.

\section{Summary and Perspectives}

\subsection{What can one determine?}

The examples presented above show the level of detail that can be obtained from operando studies. This includes 1) reaction mechanism evolution and how one type of reaction evolves into another, for example, in $\mathrm{LiFePO}_{4}$ the interface between solid-solution and two-phase reactions; ${ }^{[28]}{ }^{2)}$ the crystallographic distribution of the charge carrier during electrochemical charge/discharge processes; ${ }^{[38,41,42]} 3$ ) the influence of electrochemical conditions, such as voltage limits and applied current, on the electrode structure and evolution; $\left.{ }^{[5 c, 13,38]} 4\right)$ differences between operando and ex situ measurements; ${ }_{;}^{[79 a, 80]}$ 5) kinetics of structural evolution; ${ }^{[5,38]} 6$ ) functionality of composite electrodes, in which each component varies during charging/discharging $;{ }^{[90]}$ and 7) the existence of intermediate phases. ${ }^{[5 a]}$

To determine these and other electrochemical-structural relationships, optimized electrochemical cells need to be constructed that are both representative of the electrochemical performance observed in the laboratory or commercial use and also provide a diffraction signal sufficient for structural and phase-evolution questions to be addressed.

\subsection{Structural changes during cycling and electrochemical performance}

Herein, using a few brief examples in which multiple studies have been undertaken, we highlight some key findings that in situ structural-electrochemical data have provided.

First, considering $\mathrm{LiFePO}_{4}$, as shown in Section 6.3, depending on factors such as particle size, ${ }^{[91]}$ the electrode can show solely single ${ }^{[92]}$ or two-phase delithiation ${ }^{[6]}$ or a combination of both. ${ }^{[93]}$ The reaction mechanisms were probed by in situ XRPD experiments to detail these pathways and show the combined single- and two-phase reactions. For example, $40 \mathrm{~nm} \mathrm{\textrm {LiFePO } _ { 4 }}$ undergoes a solely single-phase reaction during (de)lithiation at a rate of $\mathrm{C} / 40$. The single-phase signature was the continuous shifting of the $2 \theta$ value of the $\mathrm{LiFePO}_{4}$ reflections. ${ }^{[92]}$

Recent work to explore the high current rate behavior of $\mathrm{LiFePO}_{4}$ at micron and smaller particle sizes showed the existence of an additional phase. ${ }^{[94]}$ In smaller particles, the transition to the metastable phase was shown to be single phase. ${ }^{[94]}$ In these cases, the ability to collect fast data during rapid charge/discharge of the battery was essential. One study found an extra peak characteristic of a metastable phase, ${ }^{[94 a]}$ which was related to an approximate phase composition of $\mathrm{Li}_{0.6-0.75} \mathrm{FePO}_{4}$. The cell was cycled under non-equilibrium conditions (fast), and thus, the phase was only observed under such conditions. However, in observing this phase, the interpretation of the electrochemical reaction of $\mathrm{LiFePO}_{4}$ had to be altered to take into account the rate dependence on reaction evolution. Systematically, a subsequent study illustrated the relationship between current rate and the formation of this metastable phase (single or two phase) by using in situ synchrotron XRD experiments. ${ }^{[94]}$ Therefore, time-dependent XRD data at high current rates showed details on the non-equilibrium evolution of the electrode materials to allow the identification of new metastable phases and reaction pathways at elevated rates.

A logical subsequent example is $\mathrm{NaFePO}_{4}$, which adopts the same olivine structure as that of $\mathrm{LiFePO}_{4}$ and can be synthesized by either chemical ion exchange or electrochemical methods from $\mathrm{LiFePO}_{4}$. In situ XRPD was used to determine the reaction evolution; however, $\mathrm{NaFePO}_{4}$ showed two distinct, plateau-like features in its charge/discharge curve compared with only one flat plateau in $\mathrm{LiFePO}_{4}$. This indicates the presence of an intermediate phase and researchers found that the composition was $\mathrm{Na}_{2 / 3} \mathrm{FePO}_{4}$. The electrochemically isolated and characterized $\mathrm{Na}_{2 / 3} \mathrm{FePO}_{4}$ structure was more complex (modulated) than that of the simpler parent olivine. ${ }^{[76,95]}$ Notably, researchers also predicted similar phases for related oli- 
vine-type electrodes during charging/discharging. ${ }^{[95 a]}$ A major structural difference appeared during charging and discharging: on charging there was a sequence of two two-phase reactions, whereas on discharging three phases appeared simultaneously in the ex situ XRPD data. ${ }^{[96]}$ The coexistence of three phases, $\mathrm{NaFePO}_{4}, \mathrm{Na}_{2 / 3} \mathrm{FePO}_{4}$, and $\mathrm{FePO}_{4}$, was explained by the difference in the volume of the three phases: the intermediate phase of $\mathrm{Na}_{2 / 3} \mathrm{FePO}_{4}$ helped to alleviate structural stress associated with the $\mathrm{FePO}_{4}$ to $\mathrm{NaFePO}_{4}$ transition. ${ }^{[78]}$ The asymmetry in phase evolution was related to the observed differences in the electrochemical curves. ${ }^{[97]}$

Further in situ work showed that the combination of phase transitions on charging were solid-solution between $\mathrm{NaFePO}_{4}$ to $\mathrm{Na}_{2 / 3} \mathrm{FePO}_{4}$, which corresponded to a sloping potential plateau in the charge curve and two-phase transition between $\mathrm{Na}_{2 / 3} \mathrm{FePO}_{4}$ and $\mathrm{FePO}_{4} \cdot{ }^{[78 \mathrm{p}]}$ Moreover, in situ XRPD data showed how thermodynamics and current rate played a role in the evolution of the reaction mechanism during charging/discharging. There was not an abrupt $\mathrm{Na}_{2 / 3} \mathrm{FePO}_{4}$ to $\mathrm{Na}_{x} \mathrm{FePO}_{4}$ (in which $x$ was small) transition, rather what was observed was a continuous solid-solution reaction of $\mathrm{Na}_{2 / 3} \mathrm{FePO}_{4}$ and $\mathrm{Na}_{x} \mathrm{FePO}_{4}$ during the two-phase transition. Importantly, if the current was removed, the phases relaxed back to the $\mathrm{Na}_{2 / 3} \mathrm{FePO}_{4}$ and approximately $\mathrm{FePO}_{4}$ composition. ${ }^{[78 p, 97]}$ Thus, the solid-solution-type behavior appeared to be current rate dependent. ${ }^{[97]} \mathrm{Na}_{x} \mathrm{FePO}_{4}$ electrodes appeared to show a current-dependent, thermodynamic/kinetic structural evolution during charging/discharging, which could be elucidated by in situ studies.

To give an example of how chemical composition of the electrode alters both the electrochemical response, and hence, structural evolution, we consider layered structures of the general formula $\mathrm{LiMO}_{2}$, in which $\mathrm{M}$ can be $\mathrm{Co}, \mathrm{Ni}$, and combinations of $\mathrm{Co}, \mathrm{Ni}, \mathrm{Mn}, \mathrm{Al}$, and so forth. $\mathrm{LiCoO}_{2}$ is an example of these layered structures in which the stacking axis (c) of the layered structure is shown to expand during charging and contract during discharging. ${ }^{[5 a, c, 30,40]}$ This behavior was determined by in situ NPD data at three different current rates $(\approx 2,7$, and $43 \mathrm{~h}$ for a charge and discharge cycle) on two different types of commercial batteries (pouch and cylindrical cells). ${ }^{[5 a, c]}$ Lithium removal upon charging resulted in the repulsion of the negatively charged $\mathrm{CoO}_{6}$ layers to expand the $c$ axis. Related work also showed that the $c$ lattice parameter expanded during charging and then began to stabilize at higher voltages (e.g., $>4 \mathrm{~V}$ ). ${ }^{[27]}$ Additionally, recent work on commercial electrodes containing combinations of $\mathrm{M}=\mathrm{NMC}$ and with $\mathrm{M}=\mathrm{Ni}, \mathrm{Co}$, and $\mathrm{Al}$, showed interesting stacking axis behavior near the charged state. ${ }^{[45]}$ The $\mathrm{LiNi}_{1 / 3} \mathrm{Co}_{1 / 3} \mathrm{Mn}_{1 / 3} \mathrm{O}_{2}$ (Panasonic CGR) cathodes showed an expansion of the $c$ stacking axis that equilibrated near the charged state (and during the constant potential step often applied at $4.2 \mathrm{~V}$ ), whereas the $\mathrm{Li}(\mathrm{Ni}, \mathrm{Co}, \mathrm{Al}) \mathrm{O}_{2}$ (Panasonic NCR) cathode showed an expansion of the $c$ stacking axis until the charged state and then proceeded to contract during the constant potential step. During discharging the $\mathrm{LiNi}_{1 / 3} \mathrm{Co}_{1 / 3} \mathrm{Mn}_{1 / 3} \mathrm{O}_{2}$ cathode contracted, whereas the $\mathrm{Li}(\mathrm{Ni}, \mathrm{Co}, \mathrm{Al}) \mathrm{O}_{2}$ cathode initially expanded and then contracted. ${ }^{[45]}$ Typically, the $\mathrm{Li}(\mathrm{Ni}, \mathrm{Co}, \mathrm{Al}) \mathrm{O}_{2}$ batteries were designed for high capacities with relatively low current applications, whereas the $\mathrm{LiNi}_{1 / 3} \mathrm{Co}_{1 / 3} \mathrm{Mn}_{1 / 3} \mathrm{O}_{2}$ batteries were designed for high rate charging/discharging with a lower capacity. Another in situ NPD study compared the structural evolution of $\mathrm{Li}$ $\mathrm{Ni}_{0.5} \mathrm{Co}_{0.2} \mathrm{Mn}_{0.3} \mathrm{O}_{2}$ and $\mathrm{LiCoO}_{2}$ during charging and contrasted their lattice parameter evolution. In this work, they observed a decrease in the $c$ lattice parameter of $\mathrm{LiNi}_{0.5} \mathrm{Co}_{0.2} \mathrm{Mn}_{0.3} \mathrm{O}_{2}$ near the charged state, which was directly attributed to the loss of cation mixing, that is, the partial occupation of $\mathrm{Li}$ on the $\mathrm{Ni}$ sites and vice versa, which was found at lower states of charge. This loss of cation mixing directly influenced the stacking axis (structural evolution) near the charged state of the battery. Such a range of studies illustrate that varying the chemical composition of the electrode not only influences the electrochemical performance of the electrode, but also the structural evolution of the layered phases, especially close to the charged state.

These layered cathodes have been studied by using in situ XRPD for which compositional variation with performance and structural characteristics can be correlated. An example is the work on lithium-excess $\mathrm{Li}\left(\mathrm{Li}_{0.2} \mathrm{Co}_{0.1} \mathrm{Mn}_{0.55} \mathrm{Ni}_{0.15}\right) \mathrm{O}_{2}$, which shows the expansion and contraction of the $c$ lattice parameter during charging and discharging, with a reduction in the rate of expansion near the charged state. ${ }^{[98]}$ However, during a constant voltage step at $4.5 \mathrm{~V}$, the stacking axis was shown to significantly contract from $14.421(2)$ to 14.371 (3) $\AA$ after $40 \mathrm{~h}$ at $4.5 \mathrm{~V}$, and this contracted lattice parameter corresponded to the equivalent found at $4.2 \mathrm{~V}$. This behavior was considered to be related to the structural stability of the delithiated electrode at the charged state.

A recent study summarized the relationship between the $a(b)$ and $c$ lattice parameters and volume of a number of layered materials. ${ }^{[99]}$ The authors suggested the concept of "normal" and "abnormal" layered materials during lithium insertion/extraction. The normal materials (e.g., $\mathrm{M}=\mathrm{Mn}, \mathrm{Co}$, and $\mathrm{Ni}$ in $\mathrm{LiMO}_{2}$ ) showed a stacking axis expansion for the majority of charge (and contraction of the $a(b)$ axes) until near the charged state, after which they could collapse. The abnormal case, exemplified by $\mathrm{Li}_{2} \mathrm{MoO}_{3}$, showed an expansion of the $a(b)$ axes and relatively smaller changes in the $c$ stacking axis (by in situ XRPD data). By using this information, the relationship between the type of transition metal, $\mathrm{M}$; the change in the $\mathrm{M}-\mathrm{O}$ bond length during oxidation (e.g., $\mathrm{M}^{2+}$ to $\mathrm{M}^{3+}$ ); and the influence of the $M-M$ bond length was proposed to characterize how the lattice parameters would evolve. Essentially, these competing factors would determine how the crystal structure would evolve, and hence, the electrode stability during cycling (e.g., the stability of the stacking axis after 100 or $1000 \mathrm{~s}$ of cycles). It is these relationships that can be determined from a sequence of compositional, electrochemical, and (in situ) structural data.

\subsection{Mixing worlds: Getting the electrochemistry as close as possible to the real thing, while collecting high-quality structural data}

Bridging the gap between structural changes in the electrode and the electrochemical performance of the battery is chal- 
lenging. In particular, with in situ NPD, researchers are often faced with a choice of whether battery performance should be optimized during NPD data collection or whether the quality of the NPD signal should be optimized. The optimization of NPD signal is often at the cost of battery performance and vice versa. However, recent stacked pouch cells and titanium-zirconium-based cells replicate the optimized electrochemistry fairly well. ${ }^{[1,35,42]}$ On the other hand, the synchrotron XRPD-based coin, Swagelok, and few-layered pouch cells relatively easily replicate optimized battery performance. This is because on a comparative scale only minor modifications of the researchtype cells need to be made to undertake in situ XRPD experiments, especially at synchrotron sources.

What causes the discrepancies between in situ XRPD and NPD cells and their electrochemical performance? Essentially, for in situ XRPD experiments (especially at synchrotron sources), small holes need to be drilled into any stainless-steel components to allow penetration (and diffraction) of the X-ray beam. These holes can simply be covered with Kapton tape or beryllium windows. Such modifications are possible due to the virtually transparent nature of X-rays to the typical light elements that make up plastic, adhesive, and beryllium. The biggest contribution these components may have is an increase in background at low angles. The major aspect that can result in the differing performance of the in situ and conventional cells is the pressure applied in the region of the window, e.g., a slightly lower pressure may result in marginally different electrochemical performance. The other drawback is that Swagelok, few-layered pouch and coin cells are not often used in commercial applications but they are used in research laboratories. To place a large commercial battery, such as an 18650, on a XRPD beam, a high-energy synchrotron X-ray source is required.

Why is in situ NPD so much more complicated? First, due to the lower intensity of neutrons impinging on the sample and lower probability of interaction (cross section), significantly more sample needs to be placed in the neutron beam. A larger sample means larger cells and typically research laboratories are unable to produce large cells, especially if the electrodes of interest are only synthesized on a gram scale. If neutrons were transparent to low-atomic-weight elements, particularly hydrogen, scaling up the cells would not be such an issue. However, hydrogen in cells results in a large background, reducing the signal to noise ratio. Additionally, all low-atomicweight components (e.g., carbon-based binders) add to either the amorphous broad features or crystalline reflections. Therefore, scaling up the cell implies a similar increase in active material and other components that make up a battery. To improve the signal to noise ratio, the other components in a battery can be substituted with components that have less hydrogen (e.g., replacing hydrogen with deuterium) or coming up with designs that remove hydrogen or other components altogether. However, simply by replacing one component, say deuterating the carbonate electrolyte, ${ }^{[100]}$ the electrochemical performance of the battery is altered. Typically, multiple components need to be substituted or modified to obtain a highquality NPD signal, and therefore, the battery performance tends to be different to that of an ideal coin-cell-type test, and often shows limited cycle life or some irreversibility. Researchers are striving towards minimizing this difference or characterizing it in detail with offline cells to better correlate structure with electrochemical properties.

Two further aspects should be noted with in situ NPD experiments: first, some researchers do use thicker electrodes to maximize signal from the electrode, while maintaining the same concentration of other components. ${ }^{[20,23,31]}$ However, in these cases, the current rate applied needs to be fairly slow to avoid polarization, but fast enough to finish the desired cycling prior to completion of the beam time. Therefore, the structure-electrochemistry correlation here is with respect to the slow current rate used. Second, due to the larger penetration depth afforded by neutrons, full commercial batteries can be investigated under conditions that represent typical usage. This is particularly interesting because cells that can be purchased off the shelf can be used and structural evolution with respect to external conditions measured, for example, the number of cycles and rate of cycling, can be compared with multiple electrode chemistries under the same conditions, such as temperature. ${ }^{[5,26,45]}$ This gives a direct correlation between electrode crystal structure and evolution with battery cycling conditions.

\subsection{In situ versus ex situ}

Ex situ measurements require either pristine materials or the extraction of materials of interest from devices before diffraction-based studies are carried out. The quality of data may be excellent, but the removal of the material from the battery raises questions about reactions with the environment, especially if the material is air sensitive, and the true state of the material. The last factor becomes important because relaxation phenomena or short circuiting during electrode extraction can change the state of charge. Researchers often equilibrate the battery, for example, for a charge at which the charging current is applied, to a certain potential and then the battery is held potentiostatically at this voltage for extended periods of time before battery deconstruction, which is often undertaken immediately. Thus, data acquired by this means provides information on the electrode in an equilibrium state, which is likely to occur on limited occasions in a functioning battery. A picture of electrode evolution can be built from electrodes extracted from batteries at various states of charge. This demonstrates another variable in ex situ experiments. To obtain multiple states of charge of the electrode, a new battery has to be made and the electrode extracted. Ideally, variables have to be minimized on the laboratory scale to ensure comparability of the ex situ datasets.

In situ or operando techniques provide a picture of electrode evolution and generally components in batteries as they function. Often a trade-off is made between the resolution and the quality of data moving from ex situ to in situ experiments. This is mainly due to the introduction of new components into the beam because ex situ data contains essentially the material of interest, whereas in situ data contains the material inside 
a functioning electrochemical cell. By using sufficiently long collection times, in situ data with good statistics can be obtained. Thus, the structure of the material of interest in a functioning cell can be probed and this can be undertaken at various points in the electrochemical cycle or with a certain amount of charge transferred. If diffraction data collection times can be reduced while obtaining sufficient quality data, operando measurements can be attempted. In this case, the material of interest can be tracked in a time-resolved manner with respect to electrochemical cell function. Such data can then be used to obtain kinetic information on the reactions that occur at the electrodes, in addition to characterization of the structural response.

The question of which method researchers choose depends on access to instruments, the scientific question being answered, and expertise in analysis. Typically, ex situ measurements should be performed prior to any in situ work, even if this is to only characterize the starting electrode material. Ideally, other states of charge will be probed with ex situ techniques. If questions remain, in situ or operando experiments can then be performed, noting that an operando experiment can really show what is happening at the electrode relative to snapshots obtained by using ex situ data. Ex situ experiments are often needed to justify beam time for operando experiments at major facilities.

\subsection{Next steps}

All-solid-state batteries, in which the electrolyte and separator are fused into one solid-state electrolyte, are a significant advantage for in situ NPD studies, as shown above. Interestingly, considering ambient-temperature sodium-ion batteries, sodium-ion conductivity tends to be higher in solid-state compounds relative to lithium-ion conductivity, which may, in the future, lend itself to all-solid-state sodium-ion batteries. Therefore, all-solid-state lithium- and sodium-ion battery in situ diffraction-based experiments are likely to appear and play a larger role in understanding the structure and function of electrodes and electrolytes simultaneously.

\section{Final Thought}

In situ and operando diffraction-based experiments are the future of battery development. Why should researchers limit themselves to solely electrochemical data (or structural data) when both electrochemical and structural data can be collected simultaneously in a single experiment?

\section{Acknowledgements}

The infrastructure and materials for the experiments were in part provided by the Energy Materials research project within the Bragg Institute. N.S. would like to acknowledge AINSE support through the Research Fellowship Scheme. Some preliminary data presented herein are part of projects working in collaboration with Dr. Timothy Khoo and Dr. Patrick Howlett from Deakin Uni- versity; Dr. Dawei Su and Prof. Guoxiu Wang from the University of Technology, Sydney; and Dr. Prasada Rao and Associate Prof. Stefan Adams from the National University of Singapore.

Keywords: electrochemistry • in situ analysis • neutron diffraction $\cdot$ structure-property relationships $\cdot$ X-ray diffraction

[1] B. Scrosati, J. Solid State Electrochem. 2011, 15, 1623-1630.

[2] K. Mizushima, P. C. Jones, P. J. Wiseman, J. B. Goodenough, Solid State lonics 1981, 3-4, 171-174.

[3] T. Nagaura, K. Tozawa, Prog. Batt. Solar Cells 1990, 9, 209.

[4] J.-M. Tarascon, M. Armand, Nature 2001, 414, 359-367.

[5] a) N. Sharma, V. K. Peterson, M. M. Elcombe, M. Avdeev, A. J. Studer, N. Blagojevic, R. Yusoff, N. Kamarulzaman, J. Power Sources 2010, 195, $8258-8266$; b) J. N. Reimers, J. R. Dahn, J. Electrochem. Soc. 1992, 139, $2091-2096$; c) N. Sharma, V. K. Peterson, Electrochim. Acta 2013, 101, $79-85$.

[6] A. K. Padhi, K. S. Nanjundaswamy, J. B. Goodenough, J. Electrochem. Soc. 1997, 144, 1188-1194.

[7] a) J.-F. Colin, V. Godbole, P. Novák, Electrochem. Commun. 2010, 12, 804-807; b) M. M. Thackeray, L. A. De Picciotto, A. De Kock, P. J. Johnson, V. A. Nicholas, T. Adendorff, J. Power Sources 1987, 21, 1-8.

[8] V. Palomares, P. Serras, I. Villaluenga, K. B. Hueso, J. Carretero-Gonzalez, T. Rojo, Energy Environ. Sci. 2012, 5, 5884-5901.

[9] T. Marks, S. Trussler, A. J. Smith, D. Xiong, J. R. Dahn, J. Electrochem. Soc. 2011, 158, A51 - A57.

[10] J. Camardese, J. Li, D. W. Abarbanel, A. T. B. Wright, J. R. Dahn, J. Electrochem. Soc. 2015, 162, A269-A277.

[11] G. Du, N. Sharma, J. A. Kimpton, D. Jia, V. K. Peterson, Z. Guo, Adv. Funct. Mater. 2011, 21, 3990-3997.

[12] S. L. Chou, Y. Pan, J. Z. Wang, H. K. Liu, S. X. Dou, Phys. Chem. Chem. Phys. 2014, 16, 20347-30359.

[13] N. Sharma, V. K. Peterson, J. Power Sources 2013, 244, 695-701.

[14] H. Kim, G. O. Park, Y. Kim, S. Muhammad, J. Yoo, M. Balasubramanian, Y.-H. Cho, M.-G. Kim, B. Lee, K. Kang, H. Kim, J. M. Kim, W.-S. Yoon, Chem. Mater. 2014, 26, 6361-6370.

[15] N. Sharma, G. Du, A. J. Studer, Z. Guo, V. K. Peterson, Solid State lonics 2011, 199-200, 37-43.

[16] O. J. Borkiewicz, B. Shyam, K. M. Wiaderek, C. Kurtz, P. J. Chupas, K. W. Chapman, J. Appl. Crystallogr. 2012, 45, 1261-1269.

[17] M. Yonemura, K. Mori, T. Kamiyama, T. Fukunaga, S. Torii, M. Nagao, Y. Ishikawa, Y. Onodera, D. S. Adipranoto, H. Arai, Y. Uchimoto, Z. Ogumi, J. Phys. Conf. Ser. 2014, 502, 012053.

[18] T. C. Hansen, H. Kohlmann, Z. Anorg. Allg. Chem. 2014, 640, 30443063.

[19] N. Sharma, M. Wagemaker in Neutron Applications in Materials for Energy (Eds.: V. K. Peterson, G. J. Kearley), Springer, Heidelberg, 2015, pp. 139-204.

[20] Ö. Bergstöm, A. M. Andersson, K. Edström, T. Gustafsson, J. Appl. Crystallogr. 1998, 31, 823-825.

[21] H. Berg, H. Rundlov, J. O. Thomas, Solid State lonics 2001, 144, 65-69.

[22] M. A. Rodriguez, D. Ingersoll, S. C. Vogel, D. J. Williams, Electrochem. Solid-State Lett. 2004, 7, A8A10.

[23] F. Rosciano, M. Holzapfel, W. Scheifele, P. Novak, J. Appl. Crystallogr. 2008, 41, 690-694.

[24] M. A. Rodriguez, M. H. Van Benthem, D. Ingersoll, S. C. Vogel, H. M. Reiche, Powder Diffr. 2010, 25, $143-148$.

[25] N. Sharma, M. V. Reddy, G. Du, S. Adams, B. V. R. Chowdari, Z. Guo, V. K. Peterson, J. Phys. Chem. C 2011, 115, 21473-21480.

[26] O. Dolotko, A. Senyshyn, M. J. Muhlbauer, K. Nikolowski, F. Scheiba, H. Ehrenberg, J. Electrochem. Soc. 2012, 159, A2082-A2088.

[27] A. Senyshyn, M. J. Muhlbauer, K. Nikolowski, T. Pirling, H. Ehrenberg, J. Power Sources 2012, 203, 126-129.

[28] N. Sharma, X. Guo, G. Du, Z. Guo, J. Wang, Z. Wang, V. K. Peterson, J. Am. Chem. Soc. 2012, 134, 7867-7873.

[29] N. Sharma, V. K. Peterson, J. Solid State Electrochem. 2012, 16, 1849 1856. 
[30] X.-L. Wang, K. An, L. Cai, Z. Feng, S. E. Nagler, C. Daniel, K. J. Rhodes, A. D. Stoica, H. D. Skorpenske, C. Liang, W. Zhang, J. Kim, Y. Qi, S. J. Harris, Sci. Rep. 2012, 2, 747.

[31] M. Bianchini, J. B. Leriche, J.-L. Laborier, L. Gendrin, E. Suard, L. Croguennec, C. Masquelier, J. Electrochem. Soc. 2013, 160, A2176-A2183.

[32] L. Cai, K. An, Z. Feng, C. Liang, S. J. Harris, J. Power Sources 2013, 236, $163-168$.

[33] V. A. Godbole, M. Hess, C. Villevieille, H. Kaiser, J. F. Colin, P. Novak, RSC Adv. 2013, 3, 757-763.

[34] C.-W. Hu, N. Sharma, C.-Y. Chiang, H.-C. Su, V. K. Peterson, H.-W. Hsieh, Y.-F. Lin, W.-C. Chou, B.-Y. Shew, C.-H. Lee, J. Power Sources 2013, 244, $158-163$.

[35] H. Liu, C. R. Fell, K. An, L. Cai, Y. S. Meng, J. Power Sources 2013, 240, $772-778$.

[36] M. Roberts, J. J. Biendicho, S. Hull, P. Beran, T. Gustafsson, G. Svensson, K. Edstrom, J. Power Sources 2013, 226, 249-255.

[37] A. Senyshyn, O. Dolotko, M. J. Muhlbauer, K. Nikolowski, H. Fuess, H. Ehrenberg, J. Electrochem. Soc. 2013, 160, A3198-A3205.

[38] N. Sharma, D. Yu, Y. Zhu, Y. Wu, V. K. Peterson, Chem. Mater. 2013, 25, $754-760$.

[39] I. A. Bobrikov, A. M. Balagurov, C.-W. Hu, C.-H. Lee, T.-Y. Chen, S. Deleg, D. A. Balagurov, J. Power Sources 2014, 258, 356-364.

[40] O. Dolotko, A. Senyshyn, M. J. Muhlbauer, K. Nikolowski, H. Ehrenberg, J. Power Sources 2014, 255, 197-203.

[41] W. K. Pang, V. K. Peterson, N. Sharma, J.-J. Shiu, S. H. Wu, Chem. Mater 2014, 26, 2318-2326.

[42] W. K. Pang, N. Sharma, V. K. Peterson, J.-J. Shiu, S. H. Wu, J. Power Sources 2014, 246, 464-472.

[43] A. Senyshyn, M. J. Muhlbauer, O. Dolotko, M. Hofmann, T. Pirling, H. Ehrenberg, J. Power Sources 2014, 245, 678-683.

[44] V. Zinth, C. von Luders, M. Hofmann, J. Hattendorff, I. Buchberger, S. Erhard, J. Rebelo-Kornmeier, A. Jossen, R. Gilles, J. Power Sources 2014, 271, $152-159$.

[45] M. Alam, T. Hanley, W. K. Pang, V. K. Peterson, N. Sharma, Powder Diffr. 2014, 29, S35-S39.

[46] W. K. Pang, V. K. Peterson, N. Sharma, J.-J. Shiu, S. H. Wu, Powder Diffr 2014, 29, S59-S63

[47] B. Vadlamani, K. An, M. Jagannathan, K. S. Ravi Chandran, J. Electrochem. Soc. 2014, 161, A1731-A1741.

[48] W. K. Pang, M. Alam, V. K. Peterson, N. Sharma, J. Mater. Res. 2015, 30, $373-380$.

[49] W. K. Pang, S. Kalluri, V. K. Peterson, S. X. Dou, Z. Guo, Phys. Chem. Chem. Phys. 2014, 16, 25377-25385.

[50] W. R. Brant, S. Schmid, G. Du, H. E. A. Brand, W. K. Pang, V. K. Peterson, Z. Guo, N. Sharma, J. Visual Exper. 2014, 93, e52284.

[51] M. Bianchini, E. Suard, L. Croguennec, C. Masquelier, J. Phys. Chem. C 2014, 118, 25947-25955.

[52] A. Senyshyn, M. J. Muhlbauer, O. Dolotko, H. Ehrenberg, J. Power Sources 2015, 282, 235-240.

[53] W. K. Pang, V. K. Peterson, J. Appl. Crystallogr. 2015, 48, 280-290.

[54] W. R. Brant, S. Schmid, G. Du, Q. Gu, N. Sharma, J. Power Sources 2013, 244, $109-114$.

[55] J. Kimpton, Q. Gu, Synch. Rad. News 2014, 27, 18-20.

[56] R. J. Gummow, N. Sharma, R. Feng, G. Han, Y. He, J. Electrochem. Soc 2013, 160, A1856-A1862.

[57] C. Baehtz, T. Buhrmester, N. N. Bramnik, K. Nikolowski, H. Ehrenberg, Solid State lonics 2005, 176, 1647-1652.

[58] J. B. Leriche, S. Hamelet, J. Shu, M. Morcrette, C. Masquelier, G. Ouvrard, M. Zerrouki, P. Soudan, S. Belin, E. Elkaim, F. Baudelet, J. Electrochem. Soc. 2010, 157, A606-A610.

[59] Y. Shen, E. E. Pedersen, M. Christensen, B. B. Iversen, Rev. Sci. Instrum. 2014, 85, 104103.

[60] Y. Chabre, J. Pannetier, Prog. Solid State Chem. 1995, 23, 1-130.

[61] M. Ripert, J. Pannetier, Y. Chabre, C. Poinsignon, Mater. Res. Soc. Proc. 1990, 210, 359-365.

[62] M. Winter, J. O. Besenhard, M. E. Spahr, P. Novak, Adv. Mater. 1998, 10, $725-763$.

[63] Institut Laue-Langevin, https://www.ill.eu/about/movies/experiments/ d1b-alkaline-batteries, 2007.

[64] M. Latroche, A. Percheron-Guegan, Y. Chabre, C. Poinsignon, J. Pannetier, J. Alloys Compd. 1992, 189, 59-65.
[65] O. Isnard, J. Optoelectron. Adv. Mater. 2006, 8, 411-417.

[66] M. Latroche, A. Percheron-Guegan, Y. Chabre, J. Bouet, J. Pannetier, E. Ressouche, J. Alloys Compd. 1995, 231, 537-545.

[67] a) M. Latroche, Y. Chabre, B. Decamps, A. Percheron-Guegan, D. Noreus, J. Alloys Compd. 2002, 334, 267-276; b) M. Latroche, Y. Chabre, A. Percheron-Guegan, O. Isnard, B. Knosp, J. Alloys Compd. 2002, 330-332, 787-791; c) M. Latroche, A. Percheron-Guegan, Y. Chabre, J. Alloys Compd. 1999, 293-295, 637-642; d) S. Vivet, M. Latroche, Y. Chabre, J. M. Joubert, B. Knosp, A. Percheron-Guegan, Physica B 2005, 362, 199-207; e) F. Bardé, M. R. Palacin, Y. Chabre, O. Isnard, J.-M. Tarascon, Chem. Mater. 2004, 16, 3936-3948; f) M. Latroche, F. Cuevas, W.-K. Hu, D. Sheptyakov, R. V. Denys, V. A. Yartys, J. Phys. Chem. C 2014, 118, 12162-12169.

[68] M. Latroche, J. M. Joubert, A. Percheron-Guegan, O. Isnard, Physica B 2004, 350, e427-e430.

[69] J. R. Dahn, Phys. Rev. B 1991, 44, 9170-9177.

[70] a) M. Hofmann, R. Gilles, Y. Gao, J. T. Rijssenbeek, M. J. Muhlbauer, J. Electrochem. Soc. 2012, 159, A1827-A1833; b) R. J. Bones, J. Coetzer, R. C. Galloway, D. A. Teagle, J. Electrochem. Soc. 1987, 134, 2379-2382.

[71] a) J. Rijssenbeek, Y. Gao, Z. Zhong, M. Croft, N. Jisrawi, A. Ignatov, T. Tsakalakos, J. Power Sources 2011, 196, 2332-2339; b) V. Zinth, S. SeidImayer, N. Zanon, G. Crugnola, M. Schulz, R. Gilles, M. Hofmann, J. Electrochem. Soc. 2015, 162, A384-A391.

[72] S. Y. Hong, Y. Kim, Y. Park, A. Choi, N.-S. Choi, K. T. Lee, Energy Environ. Sci. 2013, 6, 2067-2081

[73] R. Berthelot, D. Carlier, C. Delmas, Nat. Mater. 2011, 10, 74-80.

[74] F. Sauvage, L. Laffont, J. M. Tarascon, E. Baudrin, Inorg. Chem. 2007, 46, 3289-3294.

[75] X. Xia, J. R. Dahn, Electrochem. Solid-State Lett. 2012, 15, A1-A4.

[76] P. Moreau, D. Guyomard, J. Gaubicher, F. Boucher, Chem. Mater. 2010, $22,4126-4128$.

[77] F. Sauvage, E. Quarez, J. M. Tarascon, E. Baudrin, Solid State Sci. 2006, $8,1215-1221$

[78] a) X. Yu, H. Pan, W. Wan, C. Ma, J. Bai, O. Meng, S. N. Ehrlich, Y.-S. Hu, X. Q. Yang, Nano Lett. 2013, 13,4721-4727; b) C. Vidal-Abarca, J. M. Ateba Mba, C. Masquelier, J. L. Tirado, P. Lavela, J. Electrochem. Soc 2012, 159, A1716-A1721; c) Z. Lu, J.R. Dahn, J. Electrochem. Soc. 2001, 148, A1225-A1229; d) L. D. Ellis, T. D. Hatchard, M. N. Obrovac, J. Electrochem. Soc. 2012, 159, A1801-A1805; e) S. Patoux, G. Rousse, J. B. Leriche, C. Masquelier, Chem. Mater. 2003, 15, 2084-2093; f) M. Sathiya, K. Hemalatha, K. Ramesha, J.-M. Tarascon, A. S. Prakash, Chem. Mater. 2012, 24, 1846-1853; g) Z. Jian, W. Han, X. Lu, H. Yang, Y.-S. Hu J. Zhou, Z. Zhou, J. Li, W. Chen, D. Chen, L. Chen, Adv. Energy Mater 2013, 3, 156-160; h) J. J. Ding, Y. N. Zhou, Q. Sun, X. Q. Yu, X. Q. Yang Z.W. Fu, Electrochim. Acta 2013, 87, 388-393; i) Y. Sun, L. Zhao, H. Pan, X. Lu, L. Gu, Y.-S. Hu, H. Li, M. Armand, Y. Ikuhara, L. Chen, X. Huang, Nat. Commun. 2013, 4, 1870; j) S. Tepavcevic, H. Xiong, V. R. Stamenkovic, X. Zuo, M. Balasubramanian, V. B. Prakapenka, C. S. Johnson, T. Rajh, ACS Nano 2012, 6, 530-538; k) Y.-N. Zhou, J. J. Ding, K.-W. Nam, X. Yu, S.-M. Bak, E. Hu, J. Liu, J. Bai, H. Li, Z. W. Fu, J. Mater. Chem. A 2013, 1, 11130-11134; I) B. Koo, S. Chattopadhyay, T. Shibata, V. B. Prakapenka, C. S. Johnson, T. Rajh, E. V. Shevchenko, Chem. Mater 2013，25，245-252; m) H. Chen, Q. Hao, O. Zivkovic, G. Hautier, L.-S. Du, Y. Tang, Y.-Y. Hu, X. Ma, C. P. Grey, G. Ceder, Chem. Mater. 2013, 25, 2777-2786; n) T. Shimono, D. Tanabe, W. Kobayashi, H. Nitani, Y. Moritomo, J. Phys. Soc. Jpn. 2013, 82, 124717; o) J. C. Pérez-Flores, C. Baehtz, A. Kuhn, F. Garcia-Alvarado, J. Mater. Chem. A 2014, 2, $1825-$ 1833 ; p) M. Galceran, D. Saurel, B. Acebedo, V. V. Roddatis, E. Martin, T. Rojo, M. Casas-Cabanas, Phys. Chem. Chem. Phys. 2014, 16, $8837-$ 8842 ; q) L. Baggetto, H.-Y. Hah, C. E. Johnson, C. A. Bridges, J. A. Johnson, G. M. Veith, Phys. Chem. Chem. Phys. 2014, 16, 9538-9545; r) J.-H. Cheng, C.-J. Pan, J. F. Lee, J.-M. Chen, M. Guignard, C. Delmas, D. Carlier, B. J. Hwang, Chem. Mater. 2014, 26, 1219-1225; s) W. Huang, J. Zhou, B. Li, J. Ma, S. Tao, D. Xia, W. Chu, Z. Wu, Sci. Rep. 2014, 4, 4188; t) K. Shen, M. Wagemaker, Inorg. Chem. 2014, 53, 8250-8256; u) B. Mortemard de Boisse, D. Carlier, M. Guignard, L. Bourgeois, C. Delmas, Inorg. Chem. 2014, 53, 11197-11205; v) A. K. Rai, L. T. Anh, J. Gim, V. Matthew, J. Kim, Ceram. Int. 2014, 40, $2411-2417$.

[79] a) P. Serras, V. Palomares, T. Rojo, H. E. A. Brand, N. Sharma, J. Mater. Chem. A 2014, 2, 7766-7779; b) N. Sharma, P. Serras, V. Palomares, 
H. E. A. Brand, J. Alonso, P. Kubiak, M. L. Fdez-Gubieda, T. Rojo, Chem. Mater. 2014, 26, $3391-3402$.

[80] P. Serras, V. Palomares, J. Alonso, N. Sharma, J. M. Lopez del Amo, P. Kubiak, M. L. Fdez-Gubieda, T. Rojo, Chem. Mater. 2013, 25, $4917-$ 4925.

[81] J. Agrisuelas, J. J. García-Jareno, F. Vicente, J. Phys. Chem. C 2012, 116, $1935-1947$.

[82] J. C. Pramudita, S. Schmid, T. Godfrey, T. Whittle, M. Alam, T. Hanley, H. E. A. Brand, N. Sharma, Phys. Chem. Chem. Phys. 2014, 16, 2417824187.

[83] G. Girishkumar, B. McCloskey, A. C. Luntz, S. Swanson, W. Wilcke, J. Phys. Chem. Lett. 2010, 1, 2193-2203.

[84] B. Scrosati, J. Garche, J. Power Sources 2010, 195, 2419-2430.

[85] N. Jayaprakash, J. Shen, S. S. Moganty, A. Corona, L. A. Archer, Angew. Chem. 2011, 123, 6026-6030.

[86] J. Hassoun, B. Scrosati, Angew. Chem. Int. Ed. 2010, 49, 2371-2374 Angew. Chem. 2010, 122, $2421-2424$.

[87] a) L. X. Yuan, J. K. Feng, X. P. Ai, Y. L. Cao, S. L. Chen, H. X. Yang, Electrochem. Commun. 2006, 8, 610-614; b) S. S. Jeong, Y. T. Lim, Y. J. Choi, G. B. Cho, K. W. Kim, H. J. Ahn, K. K. Cho, J. Power Sources 2007, 174 $745-750$.

[88] A. K. Thapa, Y. Hidaka, H. Hagiwara, S. Ida, T. Ishihara, J. Electrochem Soc. 2011, 158, A1483-A1489.

[89] R. P. Rao, N. Sharma, V. K. Peterson, S. Adams, Solid State lonics 2013, 230, $72-76$.

[90] Z. Yang, G. Du, Z. Guo, X. Yu, Z. Chen, S. Cheng, N. Sharma, H. Liu, Electrochem. Commun. 2011, 13, 46-49.

[91] M. Wagemaker, D. P. Singh, W. J. H. Borghols, U. Lafont, L. Haverkate, V. K. Peterson, F. M. Mulder, J. Am. Chem. Soc. 2011, 133, 10222-10228.

[92] P. Gibot, M. Casas-Cabanas, L. Laffont, S. Levasseur, P. Carlach, S. Hamelet, J.-M. Tarascon, C. Masquelier, Nat. Mater. 2008, 7, $741-747$.
[93] A. Yamada, H. Koizumi, S. Nishimura, N. Sonoyama, R. Kanno, M. Yonemura, T. Nakamura, Y. Kobayashi, Nat. Mater. 2006, 5, 357-360.

[94] a) Y. Orikasa, T. Maeda, Y. Koyama, H. Murayama, K. Fukuda, H. Tanida, H. Arai, E. Matsubara, Y. Uchimoto, Z. Ogumi, J. Am. Chem. Soc. 2013, 135, 5497-5500; b) Y. Orikasa, T. Maeda, Y. Koyama, H. Murayama, K. Fukuda, H. Tanida, H. Arai, E. Matsubara, Y. Uchimoto, Z. Ogumi, Chem. Mater. 2013, 25, 1032-1039; c) H. Liu, F. C. Strobridge, O. J. Borkiewicz, K. M. Wiaderek, K. W. Chapman, P. J. Chupas, C. P. Grey, Science 2014 344, 1252817.

[95] a) M. Galceran, V. Roddatis, F. J. Zuniga, J. M. Perez-Mato, B. Acebedo, R. Arenal, I. Peral, T. Rojo, M. Casas-Cabanas, Chem. Mater. 2014, 26, 3289-3294; b) F. Boucher, J. Gaubicher, M. Cuisinier, D. Guyomard, P. Moreau, J. Am. Chem. Soc. 2014, 136, 9144-9157.

[96] M. Casas-Cabanas, V. V. Roddatis, D. Saurel, P. Kubiak, J. Carretero-Gonzalez, V. Palomares, P. Serras, T. Rojo, J. Mater. Chem. 2012, 22, 17421 17423.

[97] J. Gaubicher, F. Boucher, P. Moreau, M. Cuisinier, P. Soudan, E. Elkaim, D. Guyomard, Electrochem. Commun. 2014, 38, 104-106.

[98] D. Mohanty, S. Kalnaus, R. A. Meisner, A. S. Safat, J. Li, A. Payzant, K. Rhodes, D. L. Wood, C. Daniel, RSC Adv. 2013, 3, 7479-7485.

[99] Y.-N. Zhou, J. Ma, E. Hu, X. Yu, L. Gu, K.-W. Nam, L. Chen, Z. Wang, X. Q. Yang, Nat. Commun. 2014, 5, 5381.

[100] R. Petibon, J. Li, N. Sharma, W. K. Pang, V. K. Peterson, J. R. Dahn, Elec trochim. Acta 2015, 174, 417-423.

Received: January 30, 2015

Revised: June 23, 2015

Published online on July 29, 2015 